$203,-13$

ANL-7805

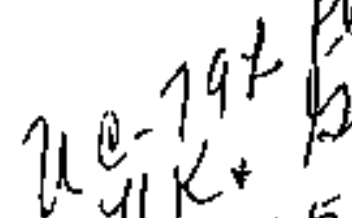

the

INTERNALLY PRESSURIZED THIN-WALL TUBES

F. L. Yaggee and Che-Yu Li

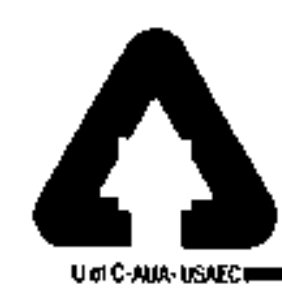

ARGONNE NATIONAL LABORATORY, ARGONNE, ILLINOIS

Prepared for the U.S. ATOMIC ENERGY COMMISSION

Uunder Contract W-31-109-Eng-38

\begin{abstract}
FaILURE MEChanisMS For
AND THEIR RELATIONSHIP TO

FUEL-ELEMENT FAILURE CRITERIA
\end{abstract}

F. L. Yaggee and Cho-Yu LI 


\section{DISCLAIMER}

This report was prepared as an account of work sponsored by an agency of the United States Government. Neither the United States Government nor any agency Thereot, nor any of their employees, makes any warranty, express or implied, or assumes any legal liability or responsibility for the accuracy, completeness, or usefulness of any information, apparatus, product, or process disclosed, or represents that its use would not infringe privately owned rights. Reference herein to any specific commercial product, process, or service by trade name, trademark, manufacturer, or otherwise does not necessarily constitute or imply its endorsement, recommendation, or favoring by the United States Government or any agency thereof. The views and opinions of authors expressed herein do not necessarlly state or reflect those of the United States Government or any agency thereof. 


\section{DISCLAIMER}

Portions of this document may be illegible in electronic image products. Images are produced from the best available original document. 
The facilitieg of Argonne National Laboratory are owned by the United States Govern. ment. Under the terms of a contract (W-31-109-Eng-3B) between the U. S. Atomic Ener(ov Commission, Argone Unuveraities Astociation and The Univeraty of Chicago, the Unuergity employs the staif and operates the Laboratory in accordance with policies and programs formulated, approved and reviewed by the Association.

\section{MEMBERS OF ARGONNE UNIVERSITIES ASSOCIATION}

The Univeresty of Aruzona

Carnegie-Mellon Unuer sity

Cate Western Reserve Unurersity

Tht Univeresty of Chicago

University of Ctheinits

Illinosg Institute of Technology

University of Illumose

Indiana Univerasty

lowa State tonversity

The University of Iowa
Kanga日 State University

The Unuer Buty of Kanans

Loyola Univer bity

Marquette Univereity

Michigen State University

The Univer suty of Muchigan

Unuversuty of Minne gota

Untversaty of Mosgour।

Nortbwestern Џiniveralty

Untver elty of Notre Dame
The Ohw State Univerasty

Ohio University

The Ptrntylyasa State Unueresty

Purdue Unuveratty

Saint Louse Unzuersity

Southern lljanos Unuveraty

The University of Texar at Austin

Washungton University

Wayne State University

The University of Wisconasn

\section{NOTICE}

This report was prepared ar an account of work spongored by the United States Government Nexther the Unuted States not the United State otomic Energy Gommission, nor any of thas employees, nor any of their contractors, aubcostrac tora, or their employee, makes any warcanty. express or umpled, or assumes any legal juablity or responstbility for the accuracy, completencse or usefulaces of any information, apparatus , product or process disclosed, or represents that 1ts ust would not infrunge privately-owned righta

Pristed an tho tunited State of America

Arajlable from

National Technical Information Service

U \& Department of Commerce

5285 Port Royal Rosd

Springfield. Vargina 22l\$1

Price Printed Copy \$3 00, Mucrofiche so os 
ANL-7805

LMFBR Fuels and Materials

Engineering and Development (UC-79b)

\section{ARGONNE NATIONAL LABORATORY \\ 9700 South Cass Avenue \\ Argonne, Illinois 60439}

\section{FAILURE MECHANISMS FOR \\ INTERNALLY PRESSURIZED THEN-WALL TUBES \\ AND THEIR RELATIONSHIP TO \\ FUEL-EL,EMENT FAILURE CRITERIA}

by

F. L. Yaggee and Che-Yu Li

Materials Science Division

December 1972

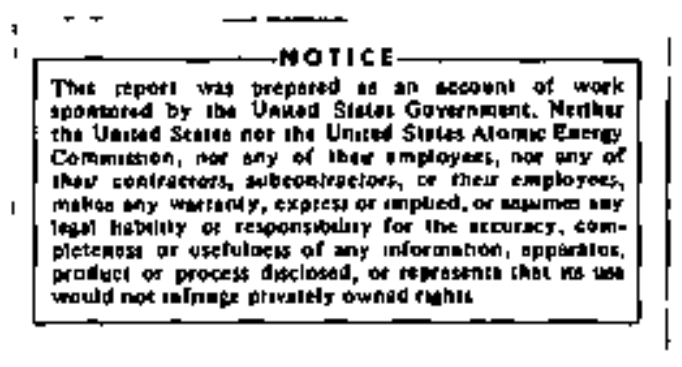


TABLE OF CONTENTS

Page

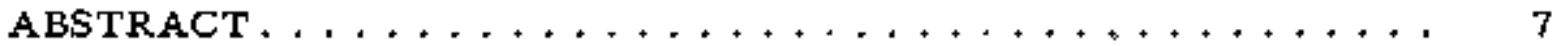

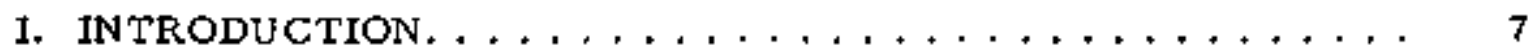

II. PLASTIC-INSTABILITY CRITERION FOR BLAXIAL

LOADING . . . . . . . . . . . . . . . . . 9

III. SPECLMEN MATERIALS AND TEST PROCEDURE. . . . . . 12

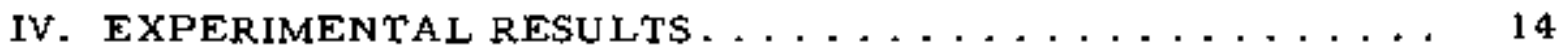

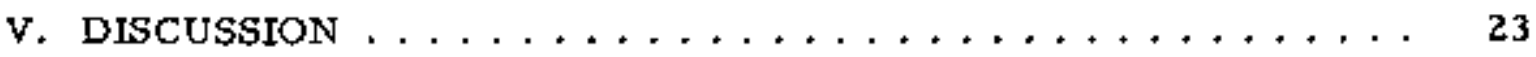

VI. FALLURE CRITERIA. . . . . . . . . . . . 30

APPENDIX: Biaxial Stress-to-Rupture Data of Other

Investigators . . . . . . . . . . . . 35

ACKNOWLEDGMENTS . . . . . . . . . . . . . . . . 40

REFERENCES $\ldots \ldots \ldots \ldots \ldots \ldots \ldots \ldots \ldots \ldots \ldots \ldots \ldots \ldots$ 4I 


\section{LIST OF FIGURES}

No,

$\underline{\text { Title }}$

Page

1. Effective Stress vs Minimum Diametral Strain Rate for Annealed Types 304 and $304 \mathrm{~L}$ Stainless Steel Tubes Tested

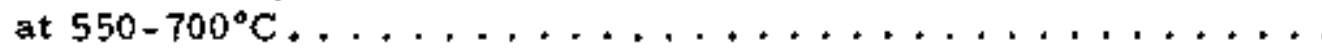

2. Density Change as a Function of Time for Annealed Type $304 \mathrm{~L}$ Stainless Steel Tubes Tested at $650^{\circ} \mathrm{C}$ at High and Low Strain Rates. . . . . . . . . . . . .

3. Transverse Section of Failed Type 304L Stainles s Steel Tube Tested at $650^{\circ} \mathrm{C}$ and Low Strain Rate . . . . . . .

4. Transverse Section of Failed Type 304L Stainless Steel Tube Tested at $650^{\circ} \mathrm{C}$ and High Strain Rate. . . . . . .

5. SEM Fractographs of Rupture and Pinhole Failures in Type $304 \mathrm{~L}$ Stainles steel Tubes Tested at $650^{\circ} \mathrm{C}$ at High and Low Strain Rates. . . . . . . . . . . . . .

6. Profiles of Rupture, Pinhole, and Fissure Failures in Annealed Types 304 and 304L Stainless Steel Tubes Tested at $650^{\circ} \mathrm{C}$ at High and Low Strain Rates . . . . . . .

7. Magnified Appearance of Rupture-, Pinhole-, and Fissurefailure Profiles shown in Fig. $6 \ldots \ldots \ldots \ldots \ldots$

8. Strain-profile Curves tor Rupture, Pinhole, and Fissure Failures shown in Fig. $6 \ldots \ldots \ldots \ldots \ldots$

9. Effect of Artificially Introduced Defects on Failure Site and Failure Strain of Annealed Type 304 Stainless Steel Tubes Tested at $650^{\circ} \mathrm{C}$ at High Strain Ratea . . . . . . . .

10. Longitudinally Oriented Intergranular Cracks That Occur on lnside Surface of Annealed Type 304L Stainless Steel Tubes Tested at $650^{\circ} \mathrm{C}$ at High and Low Strain Rates . . . . 24

11. Internal Crack Depth vs Diametral Strain for a Type $304 \mathrm{~L}$ Stainless Steel Tube Tested at $650^{\circ} \mathrm{C}$ and Low Strain Rate... .

12. Effective Stress vs Minimum Diametral Strain Rate for Annealed and EBR-II Irradiated Type 316 Stainless Steel Tubes Tested at $538-760^{\circ} \mathrm{C} \ldots \ldots \ldots \ldots \ldots \ldots$

13. Profiles of Rupture and Pinhole Failures in $\mathrm{V}-20 \mathrm{wt} \% \mathrm{Ti}$ Alloy Tubes Tested at $650^{\circ} \mathrm{C}$ at High and Low Strain Rates ...

14. Strain-profile Curves for V-20 wt $\%$ Ti Alloy Tube Failures shown in Fig. $13 \ldots \ldots \ldots \ldots \ldots \ldots \ldots$ 


\section{LIST OF FIGURES}

No. Title

Page

15. Mechanical Simulation of Grain-boundary Penetration in Thin-wall Tubes by Fission-product Attack . . . . . . . . .

16. Effective Stress vs Minimum Diametral Strain Rate for Annealed and Cold-worked Type 304 Stainless Steet Tubes Tested at $486-766^{\circ} \mathrm{C} \ldots \ldots \ldots \ldots \ldots$

17. Effective Stress vs Minimum Diametral Strain Rate for Cold-worked Type 304 Stainles $\$$ Steel Tubes Tested

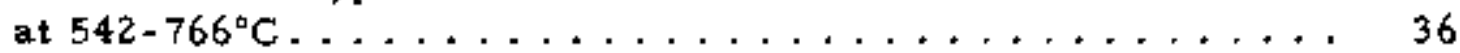

18. Effective Stress vs Minimum Diametral Strain Rate for Annealed and Cold-worked Type 316 Stainless Steel Tubes Tested at $542-766^{\circ} \mathrm{C}$ in sodium . . . . . . . . . . . .

19. Effective Stress vs Minimum Diametral Strain Rate for Annealed and Cold-worked Type 316 Stainless Steel Tubes Tested at $542-766^{\circ} \mathrm{C}$ in Helium $\ldots \ldots \ldots \ldots$

20. Effective Stress vs Minimum Diametral Strain Rate for Aged Types 304 and 316 Stainless Steel Tubes Tested at $654^{\circ} \mathrm{C} \ldots$.

21. Effective Stress vs Minimum Diametral Strain Rate for Annẹaled Type 316 Stainless Steel Tubes Tested at $738-822^{\circ} \mathrm{C}$.

22. Strain-profile Curves for Type 316 Stainless Steel Tubes Tested at $697-713^{\circ} \mathrm{C} \ldots \ldots \ldots \ldots \ldots$ 


\section{LIST OF TABLES}

No.

Titie

Page

I. Compositions and Room-temperature Mechanical Properties of Thin-wall Austenitic Stainless Steel Tubes Used in Biaxial Creep Experiments ................. 13

t]. Classification of Failure Modes for Type 316 Stainless Steel Tubes Tested at $649^{\circ} \mathrm{C} \ldots \ldots \ldots \ldots \ldots \ldots$

III. Classification of Failure Modes for Type 316 Stainless Steel Tubes Tested at $705^{\circ} \mathrm{C} \ldots \ldots \ldots . \ldots \ldots$ 


\title{
FAILURE MECHANISMS FOR \\ INTERNALLY PRESSURIZED THIN-WALL TUBES \\ AND THEIR RELATIONSHIP TO \\ FUEL-ELEMENT FAILURE CRITERLA
}

by

F. L. Yaggee and Che-Yu Li

\begin{abstract}
Tube creep-to-rupture data for internally pressurized thin-wall tubes are reviewed and analyzed. Two failure mechanisms a re apparent: (a) failure controlled by mechani cal instability (tranggranular), and (b) failure controlled by grain-boundary sliding (intergranular). The dependence of the failure mode and the strain at failure of a fuel-element cladding on stress, temperature, strain rate, and method of loading (gas pressure versus fuel swelling) are discussed. The experimental results are also presented with reference to their applicability in the formulation of fuel-element failure criteria.
\end{abstract}

\section{INTRODUCTION}

This report presents the experimental results of short-term tubeburst and longer-term creep-to-failure tests of thin-wall austenitic atainless steel tubes. The effects of stress, temperature, and strain rate on the strain at fallure and the failure mode are considered. The implications of these test results on the behavior of fuel-element cladding are discussed as they relate to the development of fuel-element failure criteria.

Primary consideration is being given to austenitic stainless steel as the fuel-element cladding in the development of the Liquid Metal Fast Breeder Reactor (LMFBR). Loading mechanisms for the cladding in the region of the fuel column can result from fuel swelling or fission-gas release, depending on the fuel-element design and operating conditions.

In the plenum volume of a fuel element located above the fuel, gaspressure loading will always be the controlling loading mechanism. In addition to the complex loading system, the cladding is simultaneously ex" posed to a hostile environment that includes radiation damage and the pos sibility of chemical attack by fission products and the liquid-sodium coolant. The mechanical loading in consort with the reactor environment will have 
a degrading effect on the cladding properties and lead to several possible failure mechanisms. Prudent fuel-element design must necessarily consider all possible synergistic effects of the total reactor environment when realistic faihure criteria are formulated. Reactor safety requirements dictate that special attention be given to abnormal reactor operating conditions.

An analysis of out-of-reactor tube-burst and creep-to-failure results shows a specific and reproducible relationship between strain at failure and the failure mode as a function of stress level, strain rate, and temperature. These results then suggest an approach that may be used in the development of criteriz for fuel-element failure.

The service temperature of the fuel cladding in the LMFBR is expected to be between 400 and $600^{\circ} \mathrm{C}\left(0.3 \mathrm{~T}_{\mathrm{m}}\right.$ to $\left.0.5 \mathrm{~T}_{\mathrm{m}}{ }^{*}\right)$. The plastic deformation of many metallic systems has been studied extensively within this temperature range, and the occurrence of grain-boundary sliding (GBS) as a deformation mechanism is well documented. Hart proposed a model to account for the strain-rate dependence of the applied stress for poly* crystalline metals, ${ }^{2,3}$ From this model, one would expect grain-matrixcontrolled deformation (GMD) at low temperatures and/or high strain rates. Under these conditions, the strain-rate sensitivity (SRS) is low. [SRS is defined as ( $\partial \ln \sigma / \partial \ln \dot{\varepsilon})_{\varepsilon}$.] At high temperatures and/or low strain rates. within the region of interest in the present report, the contribution of GBS will increase. An increase in deformation by GBS contributes to an increase of the SRS of the material, ${ }^{3,4}$ and an increase in the SRS affects the plastic instability exhibited by a polycrystalline metal.

Unstable plastic flow of metals under biaxial tension is a wellrecognized failure mode in thin wall tubes. The traditional instability criterion in uniaxial tension is based solely on the work-hardening concept originally proposed by Consideré. ${ }^{5}$ Lankford and Saibel ${ }^{6}$ have extended the work-hardening concept to thin-wall cylinders under biaxial load. However, Hart's' instability criterion is more generalized because it consider $\$$ work hardening and the SRS characteristics of a polycrystalline metal. Hart's generalized criterion is particularly relevant to the behavior of fuelelement cladding, because work hardening is absent during normal reactor operating conditions where near steady-state creep prevails. This criterion postulates that a polycrystalline metal will be plastically more atable during creep in regions where the SRS is high. As stated, the contribution of GBS becomes appreciable in the region of high SRS, making possible a change in falure mode.

In creep experiments with high-purity aluminum and aluminum alloys, Servi and Grant ${ }^{7}$ observed a consistent pattern in the transition of the failure mode from transgranular to intergranular failure as the contribution of GBS became significant. Their observations suggestanintimate

* $T_{m}$ is the absolute melting temperature. 
relation between the failure mode and the phenomena of GBS and plastic instability. On a log-log plot of stress (o) versus strain rate ( $\ddot{\varepsilon})$, the observed transition occurs at different values of strain rate as a function of temperature and grain size. Hart has proposed argurients that account for the observations of Servi and Grant. He suggests that if grain boundaries are permitted to slide (after sorme finite strain), grain-boundary cracking would be favored in the region of low and inhibited in the region of high $\dot{e}$ in the Servi and Grant experiments. Thus, in uniaxial tension tests, GBS can be expected to affect the failure mode, the axial strain at failure, and the reduction-in-area at falure: The application of this concept to the behavior of internally pressurized thin*wall tubes can have important implications in the analysis of fuel-element failures. Under fission-gas loading, cladding failure may occur either by a pinhole perfora * tion of the wall or by violent rupture, depending on the test conditions. One purpose of the present report is to establish a relationship between GBS and pinhole failures and between plastic instability and violent rupture of the cladding under fission-gas loading conditions.

Burst, stress-to-fupture, and creep tests have been conducted on thin-wall tubes under biaxial (gas pressure) loading conditions by geveral investigators in cladding development programs for LMFBR." (The data of other investigators and a discussion of the results are presented in the appendix.)

The present report extends Hart's plastic instability criterion in uniaxial tension to thin-wall tubes under biaxial load. Experimental results obtained at ANL and by other inyestigators are presented and discussed in terms of failure by both plastic instability and GBS. Finally, the applica tion of these results to the development of failure criteria for fuel element cladding are considered, and suggestions are made for further research in the area of fuel-element failure mecharisms.

\section{PLASTIC-INSTABILITY CRITERION FOR BIAXIAL LOADING}

As mentioned, Hart's' plastic-instability criterion for uniaxial tension is derived in terms of the work-hardening capacity and the SRS of a. material. Both quantities are intrinsic material properties and will be designated by $Y$ and $m$, respectively. In accordance with Hart's approach, the plastic deformation in uniaxial tension will be stable when

$$
y+m \geq 1 \text {. }
$$

In $E q \cdot 1$,

$$
\gamma=\left.\frac{1}{\sigma} \frac{\partial}{\partial \epsilon}\right|_{\dot{\varepsilon}}
$$


and

$$
\mathrm{m}=\left.\frac{\dot{\varepsilon}}{\boldsymbol{\theta}} \frac{\partial g}{\partial \dot{\varepsilon}}\right|_{\epsilon},
$$

where $\sigma$ is the applied stress, $\varepsilon$ is the true strain, and $\varepsilon$ is the true strain rate.

The following analysis for extending the plastic-instability criterion for uniaxial tension, as given in Eq. 1, to internally pressurized, thin-wall tubes is not generalized. It applies in particular to plastic instability that occurs as an ellipsoidal bulge for which the major axis is parallel to the longitudinal tube axis and is large compared with the minor axis. The instability criterion adopted for the pressurized tube is that used by Lankford and Saibe1, $6 P=0$, where $P$ is the internal pressure. The plastic deformation is stabie when

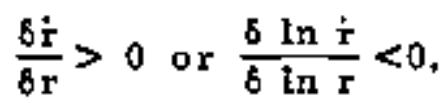

where $r$ is the tube radius, $t$ is the time derivative of $r$, and the meaning of $B$ is similar to that used by Hart." The justification of the criterion given in Eq. 2 will depend on the future development of a more generalized version for the plastic-instability criterion for internally pressurized thinwall tubes.

In accordance with Lankford and Saibel, ${ }^{6}$ we can write

$$
P=\frac{\sigma_{T}}{\mathbf{r}},
$$

where

$$
\sigma_{T}=\text { tangential stress, }
$$

and

$$
h=\text { wall thickness, }
$$

with

$$
\mathbf{h}=\mathbf{h}_{\mathbf{0}} \exp \left(-\epsilon_{T}-\epsilon_{L}\right)
$$

and

$$
r=r_{0}, \exp \left(\theta_{T}\right) .
$$

In Egs. 4 and $5, h_{0}$ and $r_{0}$ are the initial values of $h$ and $r$, respectively; $c_{T}$ and $\varepsilon_{L}$ are the tangential and axial strains, respectively. 
Following Lankford and Saibel, given $\sigma_{\mathrm{T}} / \sigma_{\mathrm{L}}=\alpha>0$ (where $\sigma_{\mathrm{L}}$ is the axial stress) and the flow equations,

$$
P=\frac{h_{0}}{r_{0}} \sigma_{T} \exp \left(-\epsilon_{T} \frac{3 \alpha}{2 \alpha-1}\right) .
$$

A conditionfor plastic instability in the pressurized thin-walled tube is

$$
\delta \mathrm{P}=\frac{\partial \mathrm{P}}{\partial \sigma_{\mathrm{T}}} \sigma_{\mathrm{T}}+\frac{\partial \mathrm{P}}{\partial \varepsilon_{\mathrm{T}}} \delta \varepsilon_{\mathrm{T}}=0 .
$$

which, when applied to Eq. 6, leads to

$$
\mathbf{r} \delta \sigma_{\mathrm{T}}+\frac{3 \alpha}{2 \alpha-\overline{1}} \sigma_{\mathrm{T}}^{8 \mathrm{r}}=0
$$

As ouming an isotropic material and-following Hart's 4 -pproach, we may write

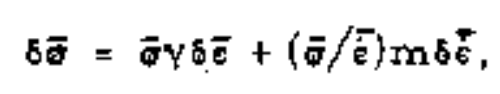

where $\bar{\delta}, \bar{\varepsilon}$, and $\overline{\dot{\varepsilon}}$ are the effective stress, strain, and strain rate, respectively, and $\gamma$ and $m$ are experimentally determined material parameters obtained in simple tension.

$$
\begin{aligned}
& \text { For the case of biaxial loading, }{ }^{6} \text { we have } \\
& \Phi=\Phi_{T} \varphi_{1}(\alpha) \\
& \bar{\varepsilon}=\epsilon \mathrm{T}^{\varphi_{2}}(\alpha)
\end{aligned}
$$

and

$$
\bar{\varepsilon}=T^{\varphi}(\alpha)
$$

where the $\varphi$ 's are functions of $\alpha$. Combining Eqs. 7 and $9 a-c$, we obtạn

$$
\delta \sigma_{T}=\sigma_{T} \gamma \varphi_{2}(\alpha) \delta \varepsilon_{T}+\frac{\sigma_{T}}{\dot{\varepsilon} T} m \dot{\tau} \mathrm{r}:
$$

The expression for $\varphi_{2}$ is derived from the definition of $\bar{c}$ and the flow equations, 6

$$
\varphi_{2}(\alpha)=\left(\frac{1-\alpha+\alpha^{2}}{\alpha-1 / 2}\right)^{1 / 2}
$$

Using Eqs. 7 and 10 and récalling that 


$$
\delta \varepsilon_{T}=\frac{\delta \mathbf{r}}{\mathbf{r}}
$$

and

$$
8 \dot{\mathrm{e}} \mathrm{T}=\frac{8 \dot{\mathbf{r}}}{\mathbf{r}}-\frac{\dot{\mathbf{r}}}{\mathbf{r}} \frac{8 \mathbf{r}}{\mathbf{r}}
$$

we may conclude

$$
\left.\frac{8 \ln \dot{r}}{8 \ln r}\right|_{P}=-\frac{\frac{-3 \alpha}{2 \alpha-1}+\varphi_{2}(\alpha) \gamma-m}{m}
$$

Therefore, the deformation of an internally pressurized thin-wall tube is stable when

$$
\varphi_{2}(\alpha) \gamma-m-\frac{3 \alpha}{2 \alpha-1}>0
$$

The criterion in Eq. 12 reduces to the result derived by Lankford and Saibel ${ }^{6}$ for a strain-hardening material that exhibits negligible strainrate dependence.

Following Hart, ${ }^{4}$ the growth of inhomogeneities in a thin-wall tube during creep deformation, where $\gamma=0$, is governed by

$$
\Delta r=\left(\frac{r_{0}}{r}\right)^{\frac{r_{3} \alpha}{(2 \alpha-1) m_{n}} t+1} \cdot \delta r_{0}
$$

Under ga $\mathrm{B} \cdot$ pressure loading conditions, $\alpha=2$. It is evident from Eq. 12 that a thin-wall tube under gas*pressure loading has a tendency toward instability, and the growth of inhomogeneities (see Eq. 13 ) is enhanced because of biaxial loading.

\section{SPECIMEN MATERIALS AND TEST PROCEDURE}

The nominal dimensions of the tube specimens used in the present creep experiments are $0.290-i n$. $O D, 0.020-i n$, wall thickness, and 4-in. length. The specimens were fabricated from AISI Types 304 and $304 \mathrm{~L}$ stainles s steel tubing obtained from two vendors. The seamless Type 304 stainless steel tubing (HT 71059) had been used for the encapsulation of experimental fuel alloys during in-reactor irradiation studies. The seamwelded Type $304 \mathrm{~L}$ stainless steel tubing ( $\mathrm{HT}$ 840505) is similar to tubing 
used for in-reactor creep experiments in EBR-II, ${ }^{10}$ Both materials were used in the solution-annealed condition (cold-worked tubing heated to $1950^{\circ} \mathrm{F}$ for $1 / 2 \mathrm{hr}$ and water-quenched) and had an ASTM 7.6 matrix grain size, The Type 304L stainless steel tubing had an ASTM 9 weld grain size. Chemical analyses for the two materials are listed in Table I.

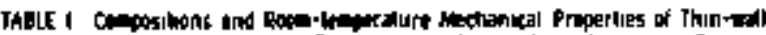

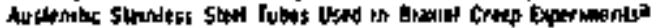

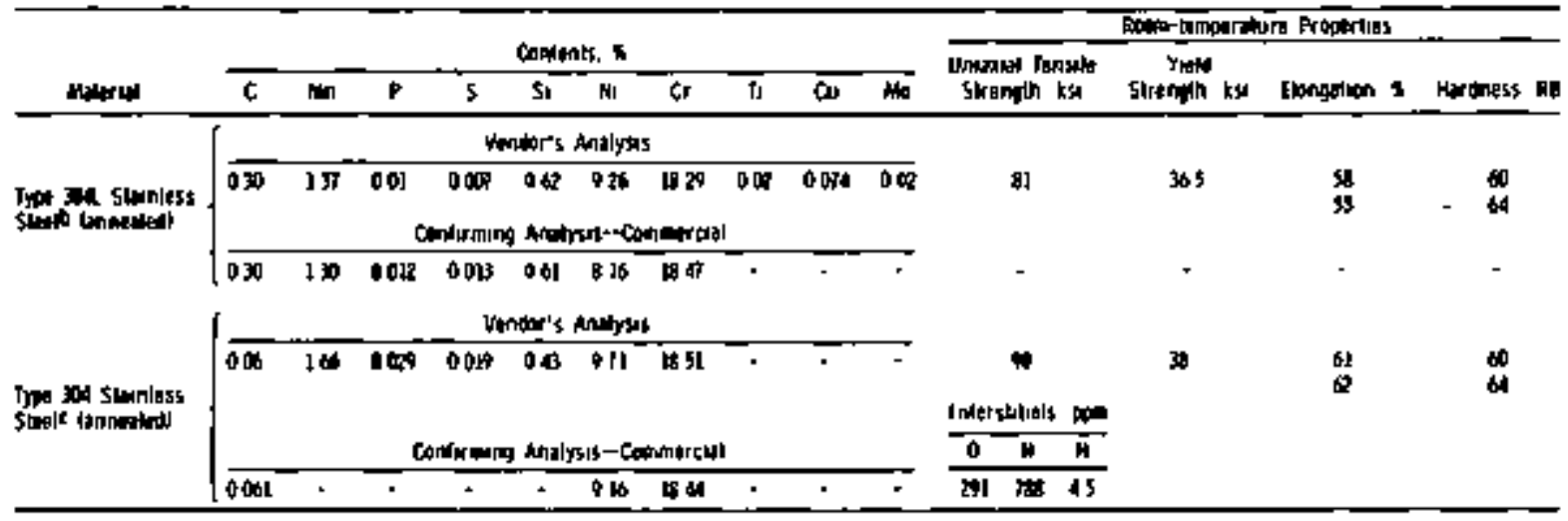

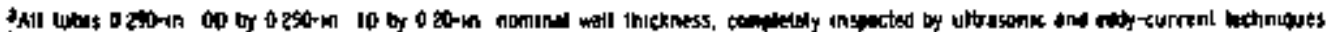
Bited bustos, wited fube ched ines, setmiless tube

Al1 specimen tubing was nondestructively inspected by eddy-current techniques and verified to be free of defects (e.g., scratches, laps, or gouges) that penetrated $>3 \%$ of the wall thickness. The selected tubing that contained defects penetrating $<3 \%$ of the wall thickness was considered to be defect-free. Artificial defects that penetrated $5 \%$ of the wall thickness were introduced into some specimens by electrical-discharge machining. The standard defect size wag 0.060 in. long by 0.005 in. wide by 0.00075 in. deep. Artificial defects were located on either the outside or inside tube surfaces at orientations parallel $\left(\beta=0^{\circ}\right)$, inclined $\left(\beta=45^{\circ}\right)$, or perpendicular $\left(\beta=90^{\circ}\right)$ to the tube axis. The purpose of the biaxial creep tests on defected specimens was to determine the effect of defects on the failure mode and failure strain. Most of the artificially defected specimens contained one defect with various combinations of defect location and orientation. Some specimens contained two defects with different combinations of location and orientation. Only those defects oriented parallel to the tube axis $\left(\beta=0^{\circ}\right)$ will be discussed.

The specimen design and test apparatus and procedure are described in Ref. 1l. The value of $\sigma_{T}$ was calculated in accordance with standard formulas. ${ }^{12}$ Posttest specimen examination included density measurements and inspection of grain size and microstructure by light microscopy. The fracture mode (intergranular versus transgranular) was determined by using scanning electron microscopy (SEM). Density measurements were made by the classical liquid-displacement method using trichloroetbylene. Specimen sections examined by light microscopy were vibratorily polished and etched with I $0 \%$ oxalic acid for microstructure detail and with $60 \%$ nitric acid for grain-size measurements. 


\section{EXPERIMENTAL RESULTS}

Results for short-term burst and long-term creep and stress-torupture tests will be given for various conditions of temperature, gtress, and resultant strain rates. Evidence will be presented to show the relationship between failure mode and the failure mechanism. In this and the remaining sections the following representations will be used for the sake of brevity: applied tangential stress $\left(\sigma_{\mathrm{T}}\right)$; Von Mises or effective stress (J); diametral strain (e), which is measured as $\Delta D / D_{0}$; diametral strain rate (e), which is measured as $(\mathrm{d} / \mathrm{dt})\left(\Delta \mathrm{D} / \mathrm{D}_{0}\right)$; minimum or steady-state strain rate $\left(\dot{\mathrm{e}}_{\mathrm{m}}\right)$ : and fracture strain $\left(e_{f}\right)$.

The two failure modes most commonly observed in biaxial creep and stress-to-rupture tests are the violent rupture (R) and the pinhole leak or fissure ( $F$ ) that perforate the tube wall. In each case. $e_{f}$ is taken as the value of $e$ at the point of failure if failure occurred within a few minutes after the last diameter measurement. It may also be taken as the value of e obtained from a duplicate, unfailed specimen that was tested simultaneously with the failed specimen and found to exhibit a similar strain profile." The time to failure is taken as the total test time to the point of los in specimen pressure. Pinhole failures are detected primarily by a gradual and unrecoverable decrease of the vacuum level in the furnace, even though the specimen pressure may be unaffected. Most pinhole leaks detected at elevated temperature are not easily located at room temperature even at a $200 \mathrm{X}$ magnification. Violent rupture failures are easily detected by a gross and sudden loss in specimen pressure.

Biaxial creep data at $550-700^{\circ} \mathrm{C}$ for Types 304 and $304 \mathrm{~L}$ stainless steel are presented in Fig. I in the form of a log-log plot of $\bar{\sigma}$ versus em. The stress and temperature dependence and the magnitude of $\dot{e}_{m}$ are

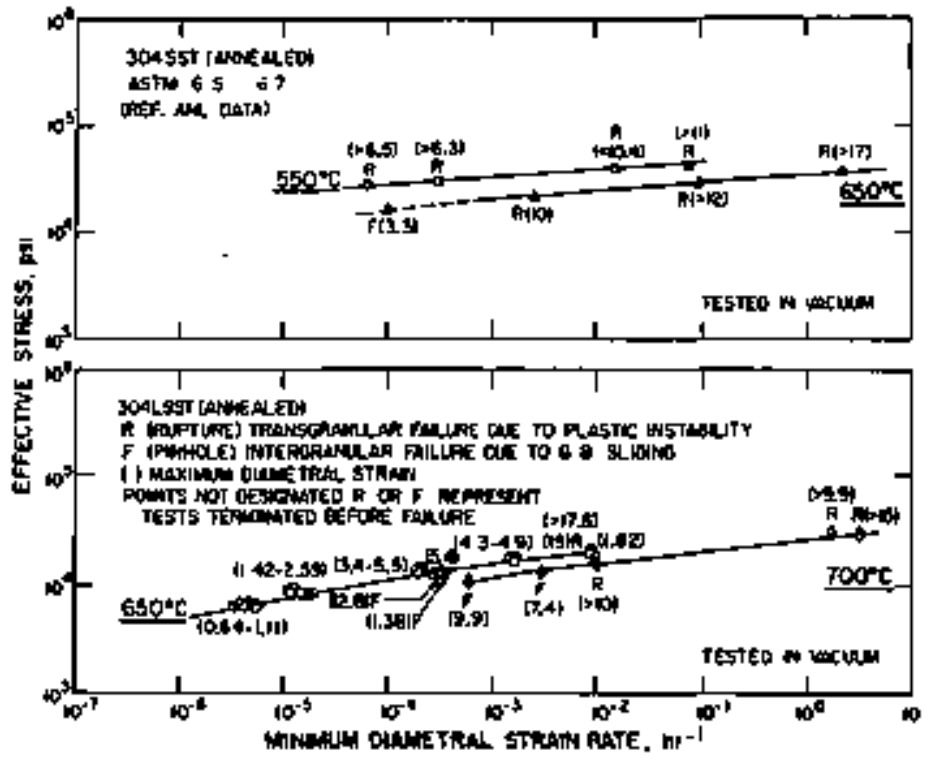

Fig. 1

Effective Stress vs Minimum Diamerral Strain Rate for Annealed Types 304 (seamless) and 304L (welded) Stainless Steel Tubes Tested at 550-700 ${ }^{\circ} \mathrm{C}$. Neg. No. MSD-54367. 
consistent with the results of other investigators. ${ }^{13-16}$ (Results of Rowe et al. are given in the appendix.) Figure 1 shows the failure mode ( $F$ or $R$ ) and $e_{f}$ for each data point. The $e_{f}$ values in percentages are given in parentheses. When two values of $e_{f}$ are given, they represent the range of values obtained from multiple specimens.

The density change for tube specimens tested at two values of $\dot{e}_{m}$ is presented in Fig. 2 in a $\log -\log$ plot as the fractional density decrease $\left(-\Delta \rho / \rho_{0}\right)$ versus the testing time. The value of $e$, in percent, for each data point is given in parentheses. Figures 3 and 4 are photomicrographs of transverse cross sections of tube specimens that indicate the size, location, and distribution of cavities for tests conducted at low and high values of $\dot{e}_{m}$. These same specimens were used to obtain the density data presented in Fig. 2. Figure 5 shows fractographs obtained by SEM from the fractured surfaces of two specimens from the same test series.

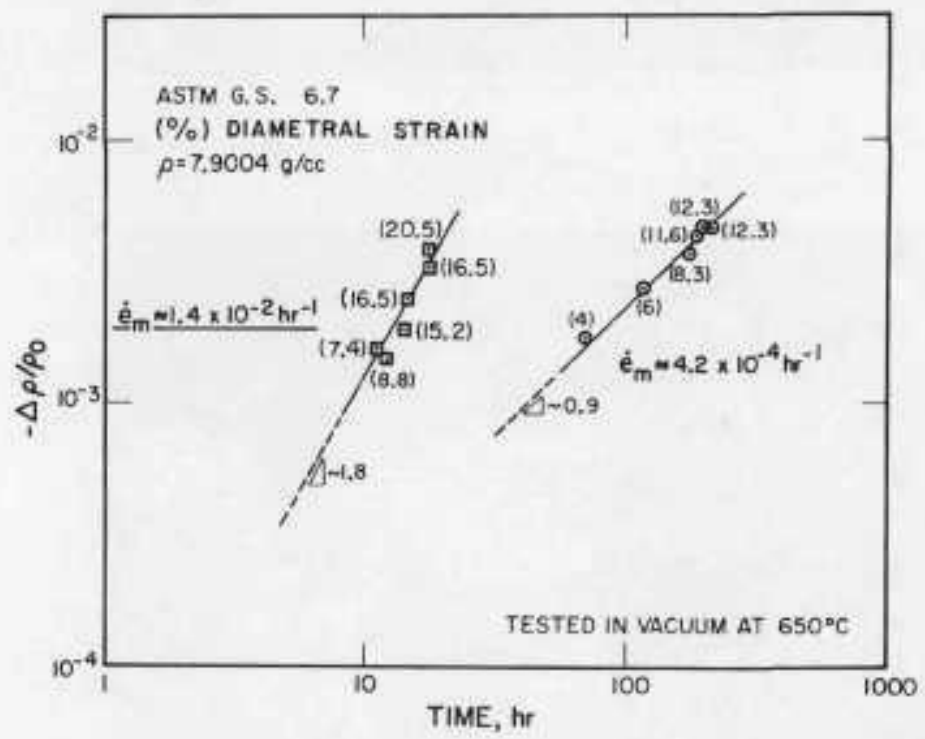

Fig. 2

Density Change as a Function of Time for Annealed Type 304L (welded) Stainless Steel Tubes Tested at $650^{\circ} \mathrm{C}$ at High and Low Strain Rates. Neg. No. MSD-54385.

Figure 6 shows the macroscopic appearance of typical tube failures obtained at high and low $\dot{e}_{m}$. The failure areas of the specimens in Fig. 6 are shown at greater magnification in Fig. 7. Strain profiles that correspond to these three specimens (see Fig. 8) indicate the extent of plastic instability that occurs at the failure site. It is clear from Fig. 8 that the development of plastic instability is influenced by a high strain rate.

Artificially introduced defects will affect the development of plastic instability in thin-wall tubes. The three specimens shown in Fig. 9 had one or more artificial defects, of the size previously mentioned, with a $\beta=0^{\circ}$ orientation. These defects were located on the outside surface of one specimen (Fig. 9a), on the inside surface of the second (Fig. 9b), and on both surfaces of the third (Fig. 9c). At $650^{\circ} \mathrm{C}$ and at high strain rates $\left(\dot{\mathrm{e}}_{\mathrm{m}}>1 \times 10^{-4} \mathrm{hr}^{-1}\right)$, the test results show the following: (a) Failure 


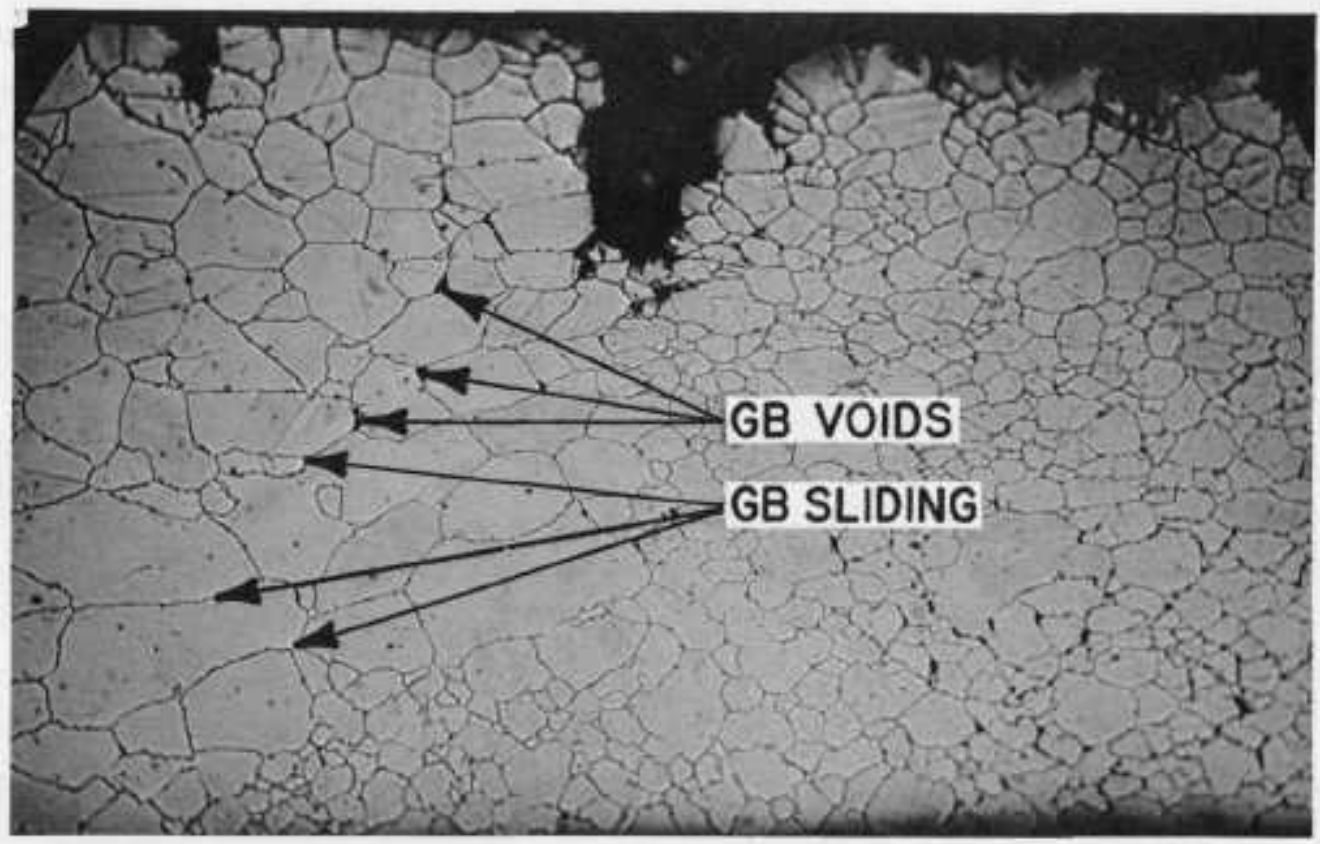

(a)

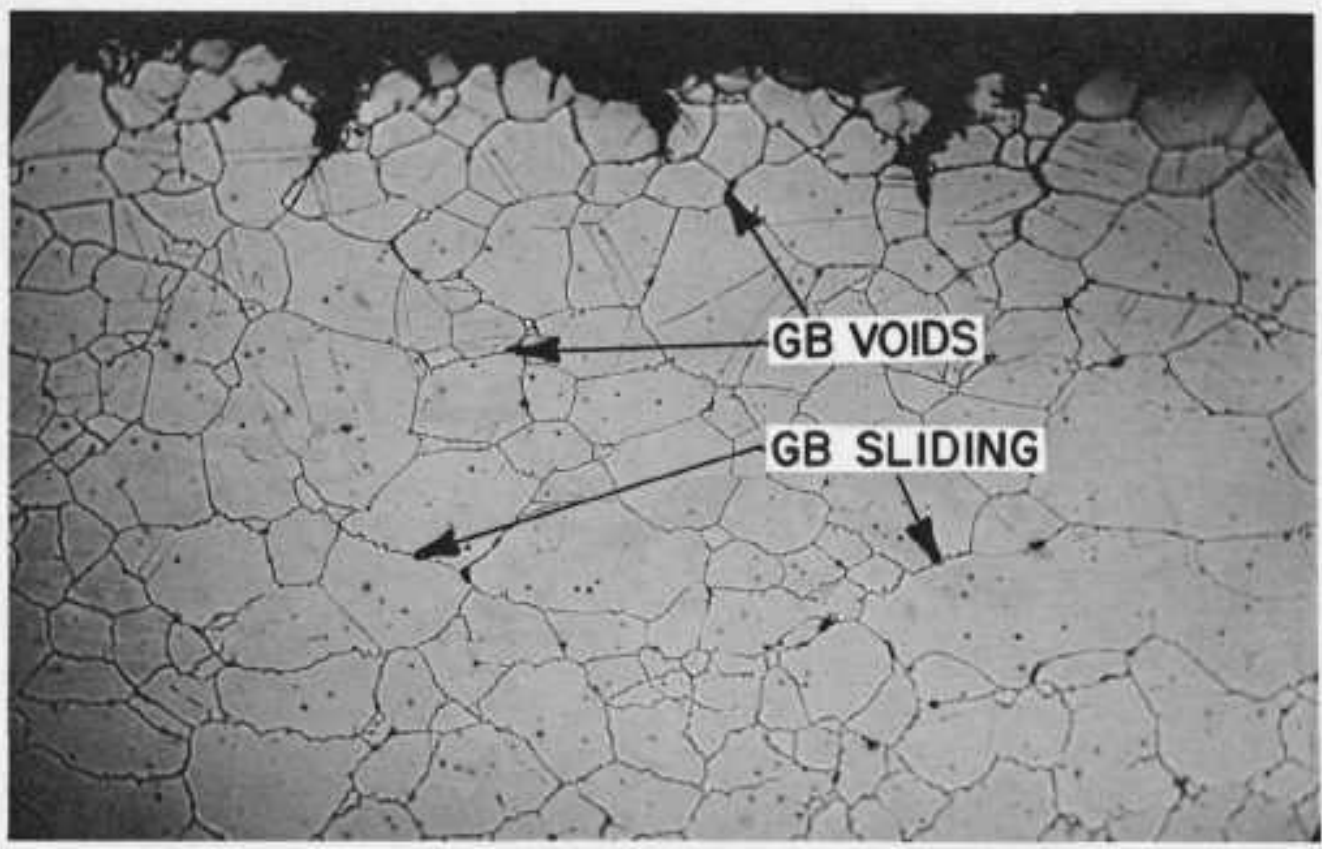

(b)

Fig. 3. Transverse Section of Falled Type 304L (welded) Stainless Steel Tube Tested at $650^{\circ} \mathrm{C}$ and Low Strain Rate $\left(\mathrm{e}_{\mathrm{m}} \approx 4.2 \times 10^{-4} \mathrm{hr}^{-1}\right)$. (a) Pinhole fallure at base metal-weld interface. Mag. 200X. Neg. No. MSD-52557. (b) Base metal $180^{\circ}$ from point of pinhole fallure. Mag. 200X. Neg. No. MSD-52453. Note grainboundary voids, equiaxed grains, and evidence of grain-boundary sliding. 


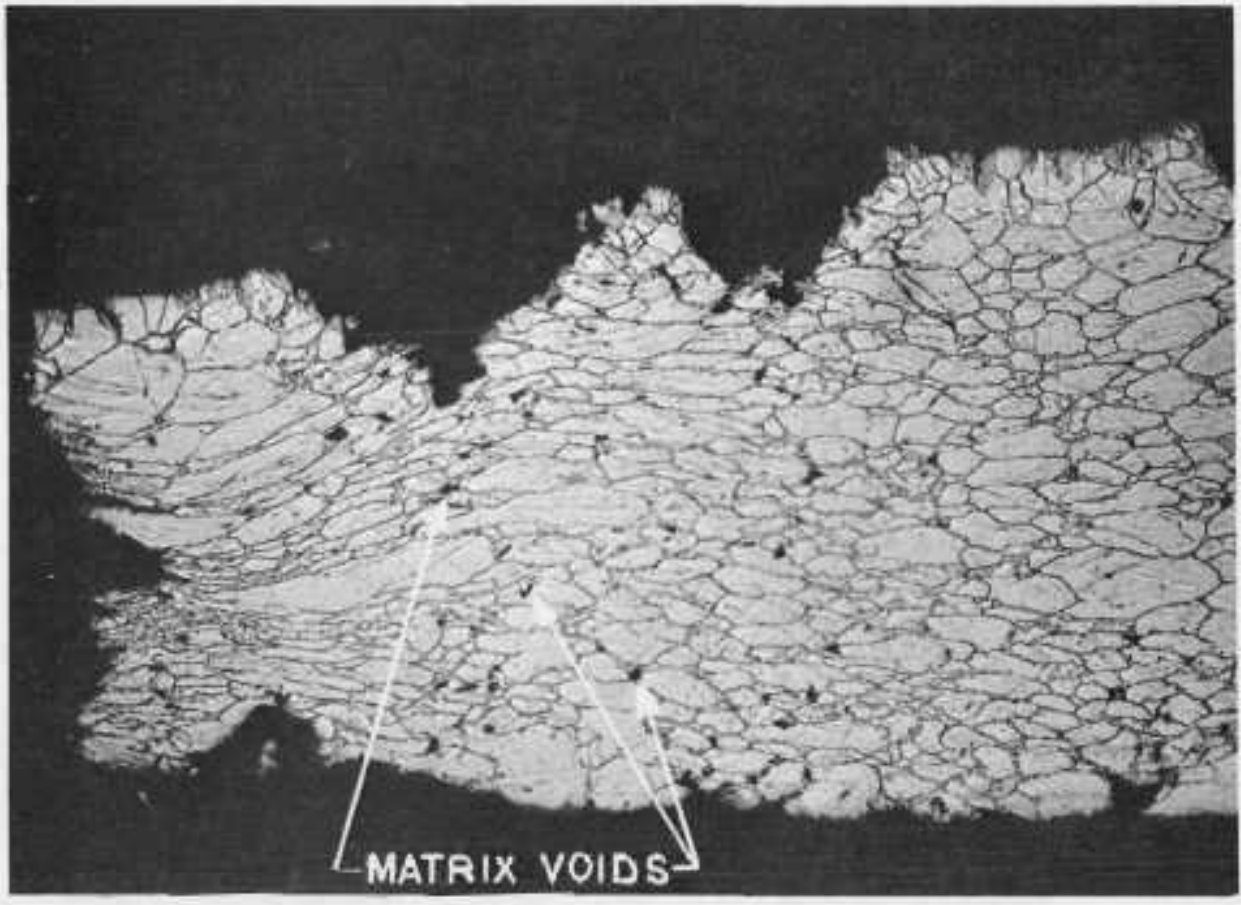

(a)

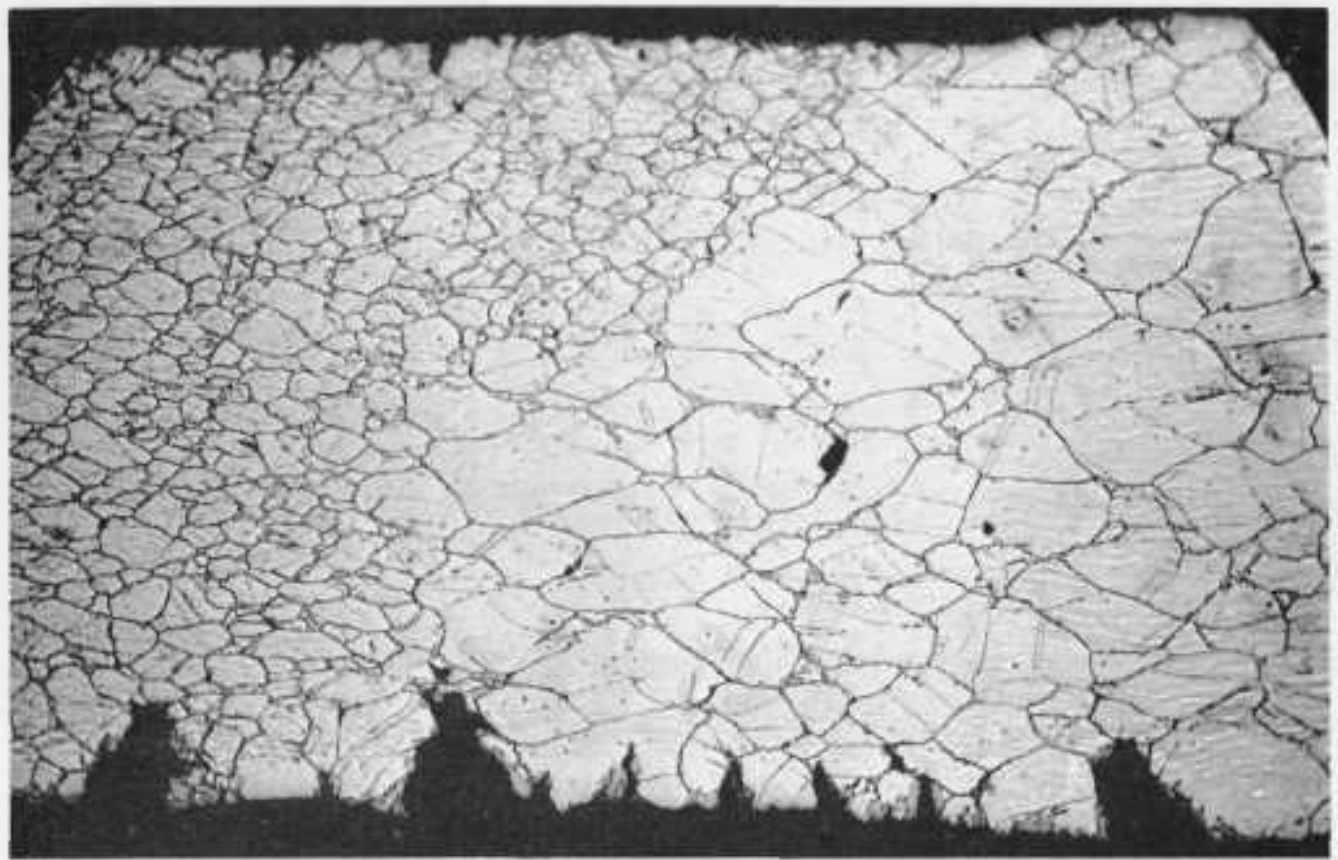

(b)

Eig. 4, Transverse Section of Falled Type 304L (welded) Stainless Steel Tube Tested at $650^{\circ} \mathrm{C}$ and High Strain Rate $\left(\dot{e}_{\mathrm{m}} \approx 1.4 \times 10^{-2} \mathrm{hr}^{-1}\right)$. (a) Ruptured edge (magniffed in Fig. 7a), Mag. 200X. Neg. No. MSD-54331. (b) Weld-base metal area $90^{\circ}$ from ruptured edge, Mag. 200X. Neg, No, MSD-54333, Note elongated grains, voids that extend into the grain matrix, and no evidence of grainboundary sliding. 

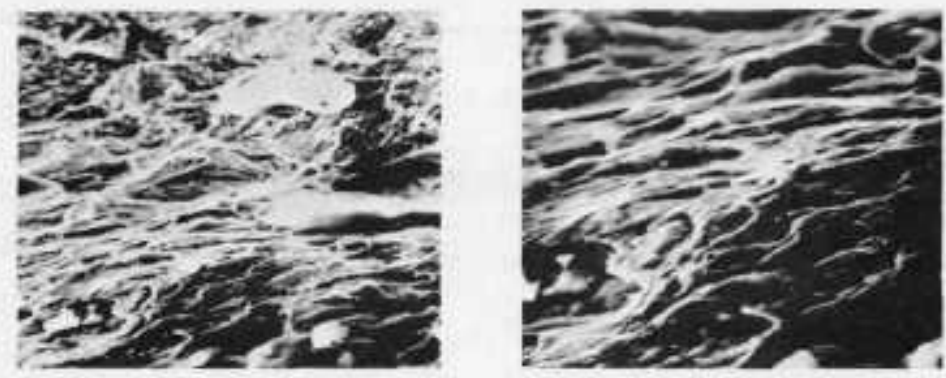

$500 \mathrm{X}$

(a)
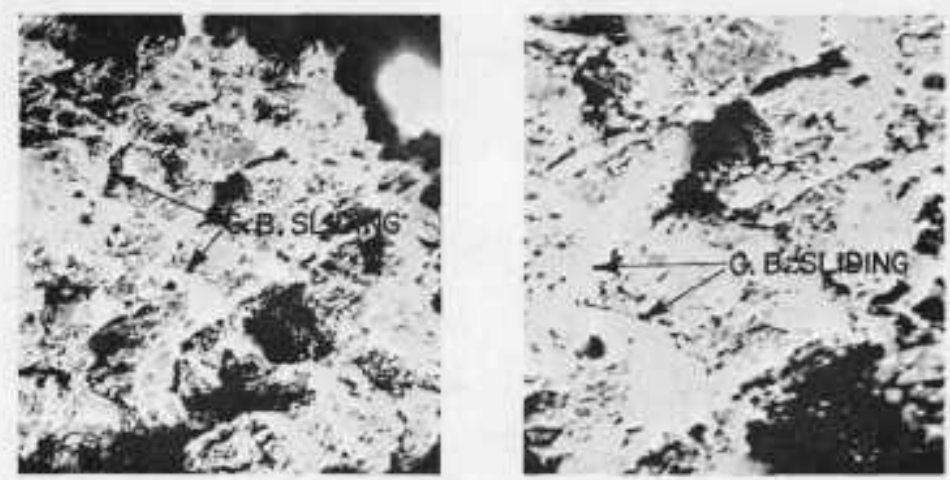

$500 \mathrm{X}$

(b)

$1000 \mathrm{X}$

Fig. 5. SEM Fractographs of Rupture and Pinhole Fallures in Type $304 \mathrm{~L}$ (welded) Stainless Steel Tubes Tested at $650^{\circ} \mathrm{C}$ at High and Low Strain Rates. (a) Ruptured edge shown in Fig. 4a. (b) Pinhole fallure shown in Fig. 3a. Note transgranular and intergranular nature of rupture and pinhole fallures that occur at high and low strain rates, respectively. Neg. No. MSD-57167. 


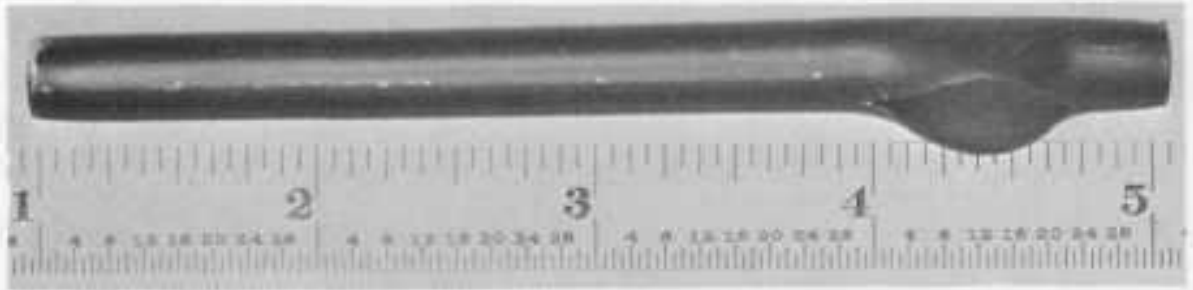

(a)

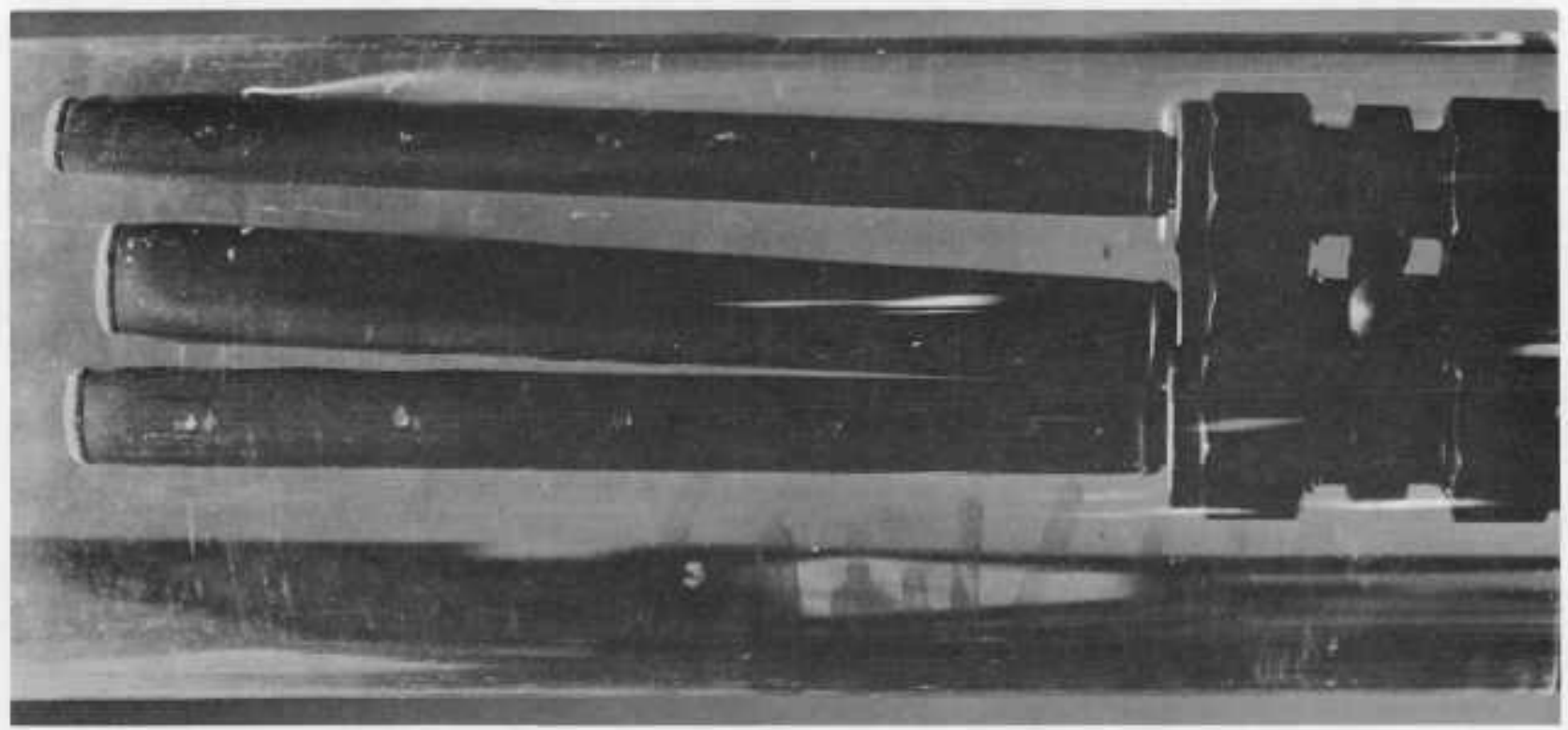

(b)

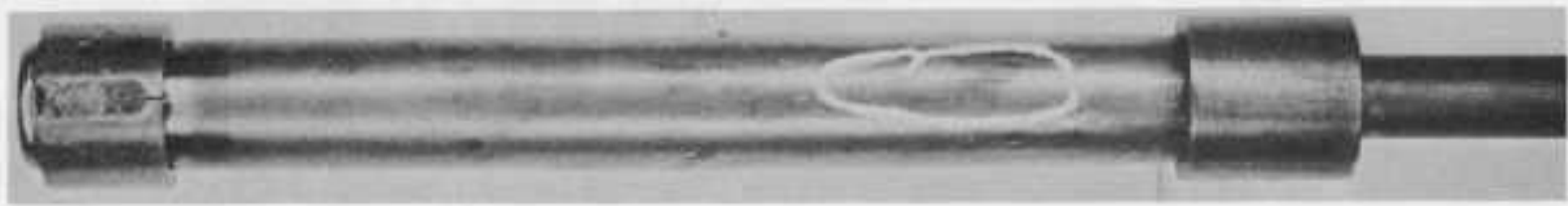

(c)

Fig. 6. Profiles of Rupture, Pinhole, and Fissure Failures in Annealed Types 304 (seamless) and 304L (welded) Stainless Steel Tubes Tested at $650^{\circ} \mathrm{C}$ at $\mathrm{High}$ and Low Strain Rates. (a) Rupture fallure shown in Figs. 4a and 5a. Mag. 1X. Neg. No. MSD-53334. (b) Pinhole failure shown in Figs. 3a and 5b. Mag. $\sim 1 X$. Neg. No. MSD-52397. (c) Fissure failure in Type 304 stainless steel tested at low strain rate $\left(\dot{e}_{m} \approx 7.5 \times 10^{-5} \mathrm{hr}^{-1}\right)$. Mag. $\sim 1 \frac{1}{2} \mathrm{X}$. Neg. No. MSD-43975. Note high local strain in rupture failure. 


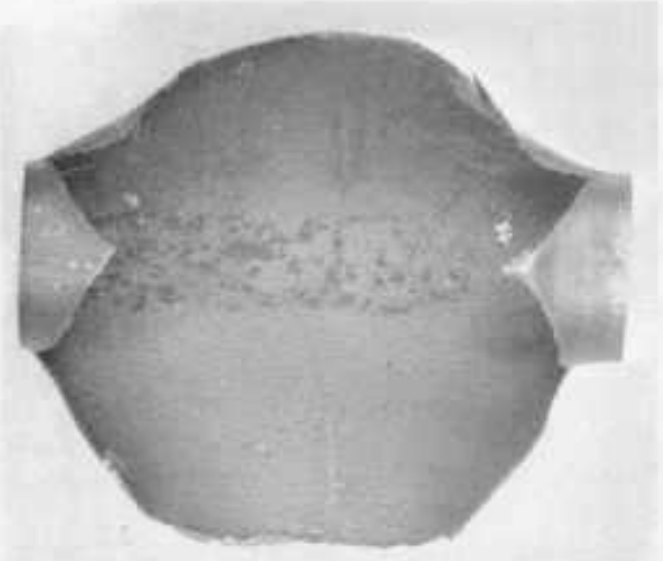

Fig. ?

Magnified Appearance of Rupture-, Pinhole-, and Fissurefallure Profiles Shown in Fig. 6. (a) Mag. $\sim 2 \frac{1}{2} X$. Neg. No, MSD-52978. (b) Mag, $\sim 8 \frac{1}{2}$ X. Neg. No. MSD-52398. (c) Mag. $\sim 9 X$. Neg. No, MSD -43977 .

(a)

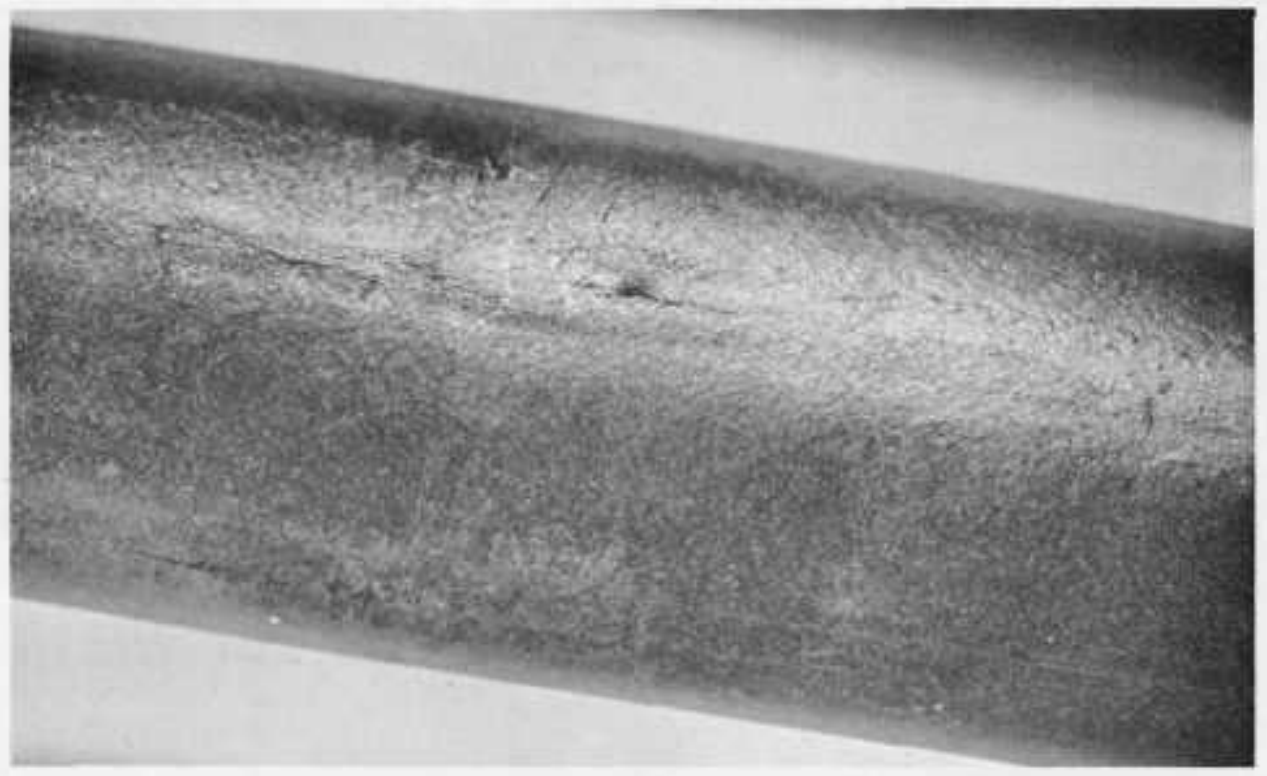

(b)

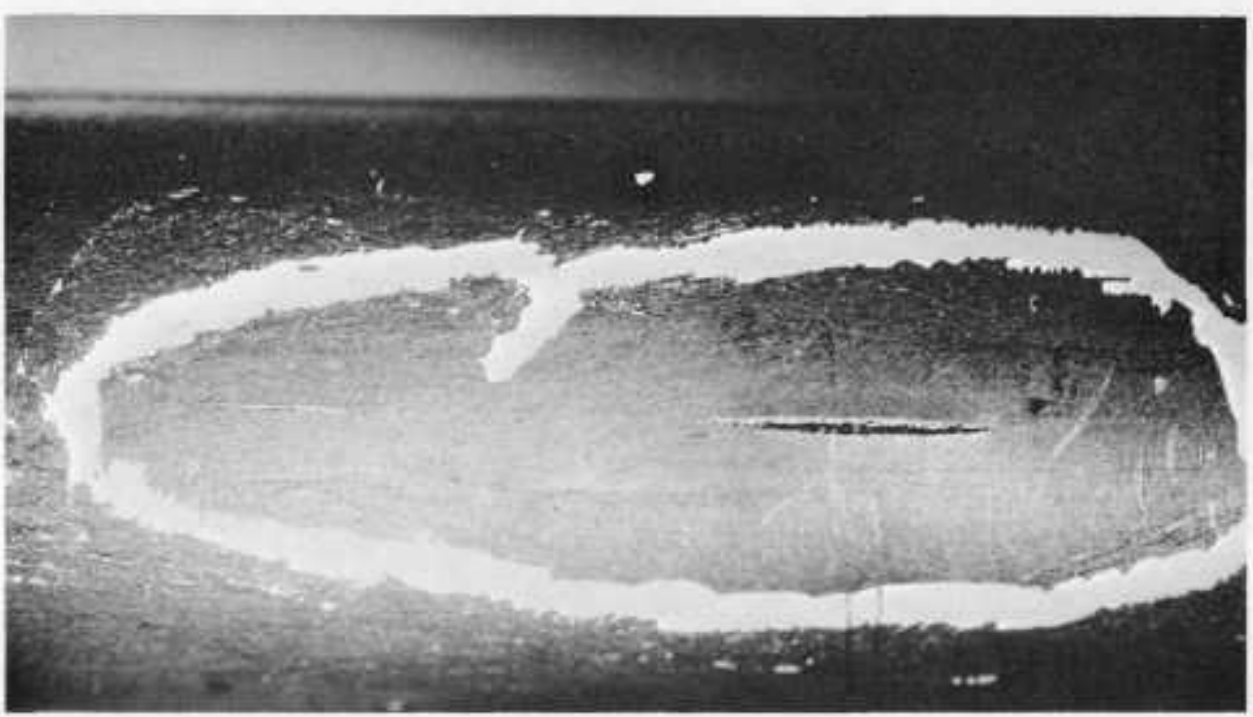

(c) 

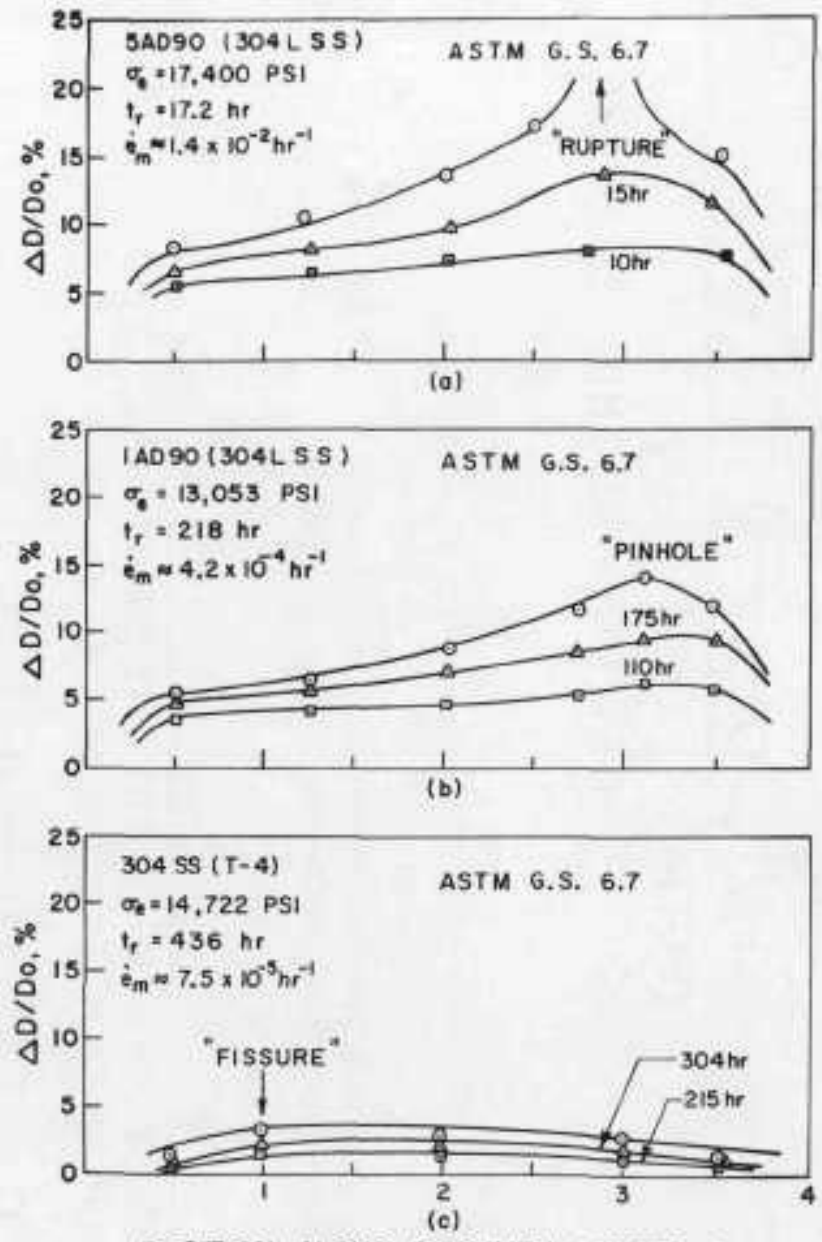

POSITION ALONG SPECIMEN LENGTH, in.

Fig. 8. Strain-profile Curves for Rupture, Pinhole, and Fissure Eailures Shown in Fig. 6. Neg. No. MSD-54375. 

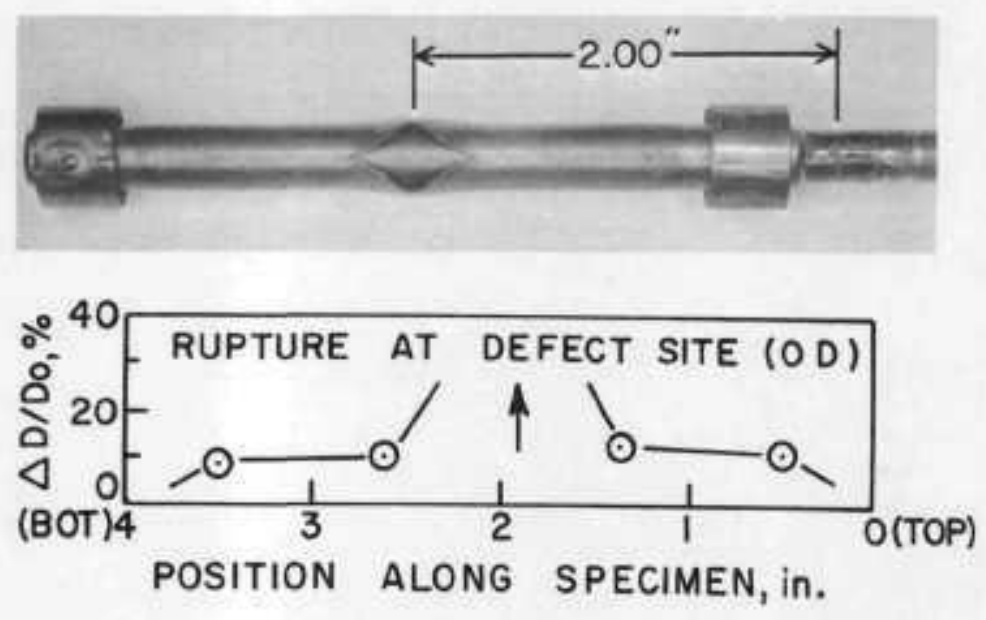

(a)
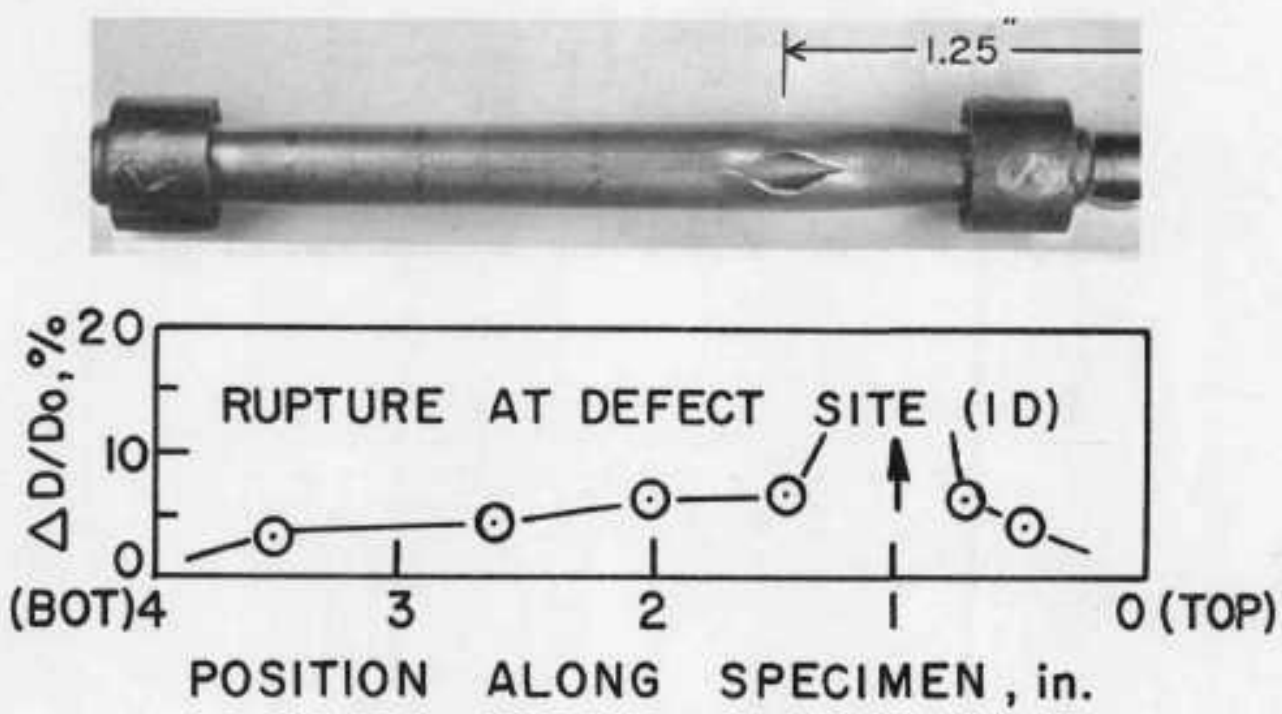

(b)
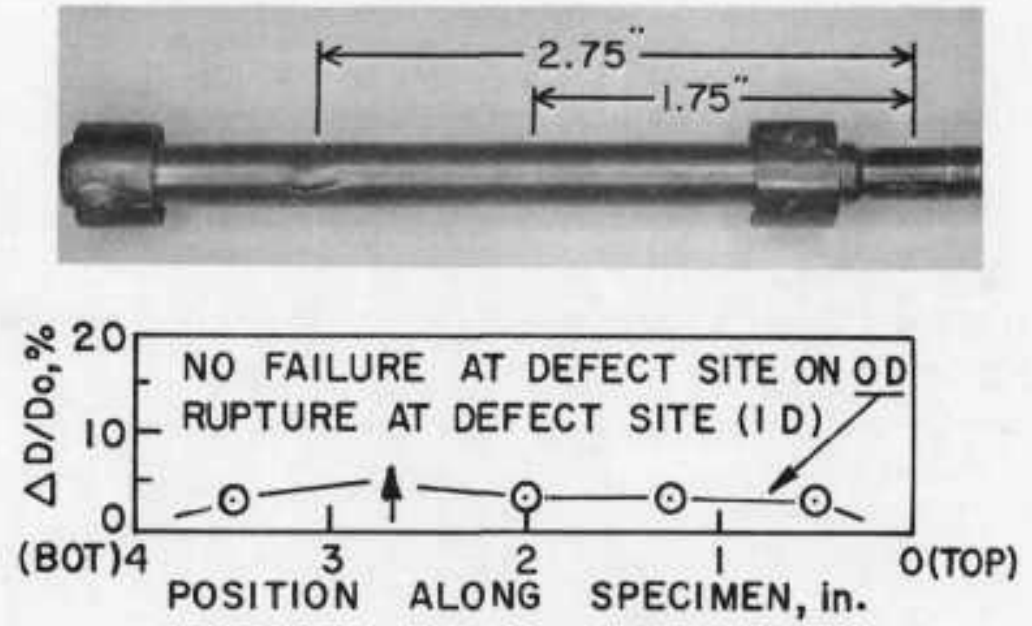

(c)

Fig. 9. Effect of Artificially Introduced Defects on Failure Site and Failure Strain of Annealed Type 304 (seamless) Stainless Steel Tubes Tested at $650^{\circ} \mathrm{C}$ at High Strain Rates. (a) Single defect on outside surface $\left(\dot{e}_{\mathrm{m}} \approx 2.8 \times 10^{-2} \mathrm{hr}^{-1}\right.$ ). (Top) Mag. $\sim 0.85 \mathrm{X}$. Neg. No. MSD-48567. (Bottom) Neg. No. MSD-54380. (b) Single defect on inside surface $\left(\dot{e}_{\mathrm{m}} \approx 5.7 \times 10^{-4} \mathrm{hr}^{-1}\right.$ ). (Top) Mag. 1X. Neg. No. MSD-48568. (Bottom) Neg. No, MSD-54378. (c) Defect on outside and inside surface $\left(\dot{e}_{\mathrm{m}} \approx 1.6 \times 10^{-2} \mathrm{hr}{ }^{-1}\right)$. (Top) Mag, $\sim 0.85 \mathrm{X}$. Neg. No, MSD -48566 . (Bottom) Neg. No. MSD-54379. Defect size: 0.062 in, 10 g by $0.005 \mathrm{in}$. wide by $0.0007 \mathrm{in}$. diameter. Note inside surface defect is preferential failure site and causes failure at lower diametral strains. 
occurred at the defect site, (b) ef was in all cases much smaller than that for similar tubes free of artificial defects, (c) location and orientation of the defect will affect $e_{f}$, and (d) the specimen in Fig. $9 b$ might have failed by pinhole leak if the specimen were defect-free because of the lower strain rate. At low strain rates $\left(\dot{e}_{\mathrm{m}} \ll 10^{-4} \mathrm{hr}^{-1}\right)$, the artificial defect used in these tests has no effect on $e_{f}$ nor on the location of the failure. These results are consistent with those in Refs, 15 and 16.

Incipient, intergranular cracks oriented parallel to the specimen axis $\left(\beta=0^{\circ}\right)$ were observed on the inside surface of specimens after finite values of $e$ were achieved. These cracks are evident in the transverse cross section shown in Fig. 10. Their depth increases with local strain, as shown quantitatively in Fig. 11 .

\section{DISCUSSION}

The purpose of this section is to identify the failure mechanisms for austenitic stainless steel thin-wall tubing under various stress and temperature conditions. Following the concepts proposed by Hart, ${ }^{2-4,8}$ it will be demonstrated that tube-specimen failures by pinhole leak are controlled by GBS, and failures by violent rupture are controlled by mechanical instability. It will also be emphasized that the magnitude of $e_{f}$ is a consequence of the controlling failure mechanism.

At elevated temperatures and high strain rates plastic deformation of polycrystalline metals will be controlled by GMD. ${ }^{8}$ Under these conditions, the contribution of GBS to the total deformation is insignificant. However, the contribution by GBS can increase to a significant level at higher strain rates if the test temperature is increased. The same effect may be achieved at constant temperature if the strain rate is decreased. Therefore, at a given temperature, an increase in GBS is associated with a decrease in strain rate and will contribute to an increase in the slope of the curve of $\log \bar{\sigma}$ versus $\log \dot{e}_{m}$. The biaxial creep data in Fig. 1 show a change in slope as a function of $\dot{e}_{m}$. This observation is supported by the biaxial stress-to-rupture data of Lovell and Barker, ${ }^{9}$ as presented in Fig. 12 (see also Figs. 16-21 in appendix).

Under nearly steady-state creep conditions, material work hardening is negligible. The mechanical stability of the specimen is then governed by the SRS. In Sec. II, it was shown that the mechanical stability of the specimen increases as the SRS increases. Inasmuch as the SRS is lower in the region of low temperature and/or high strain rate, the failure mechanism should be governed primarily by plastic instability. The failure mode to be expected is the violent rupture by transgranular fracture, and the microstructure should show elongated grains in the vicinity of the fracture. Conversely, as the temperature increases and/or the strain rate decreases, the 


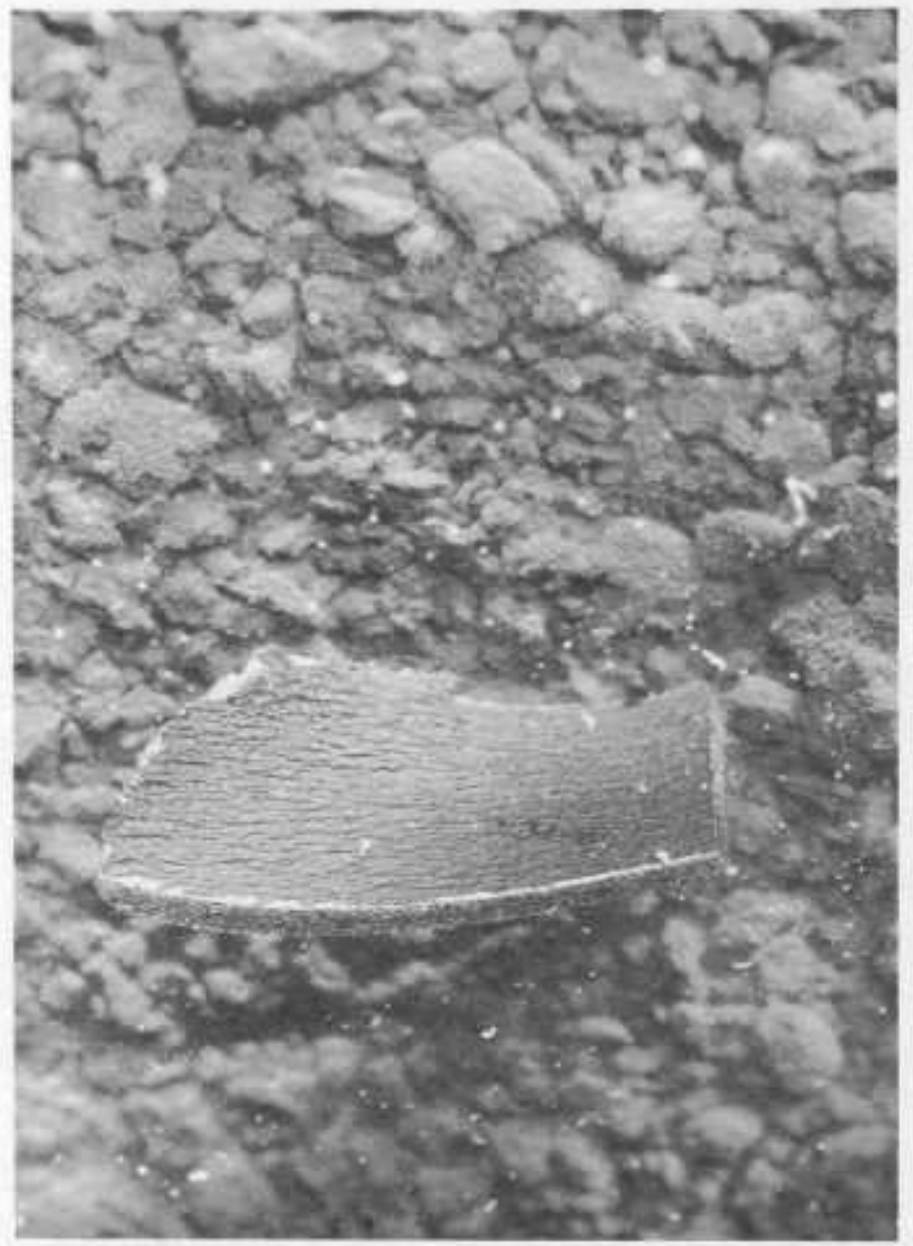

(a)

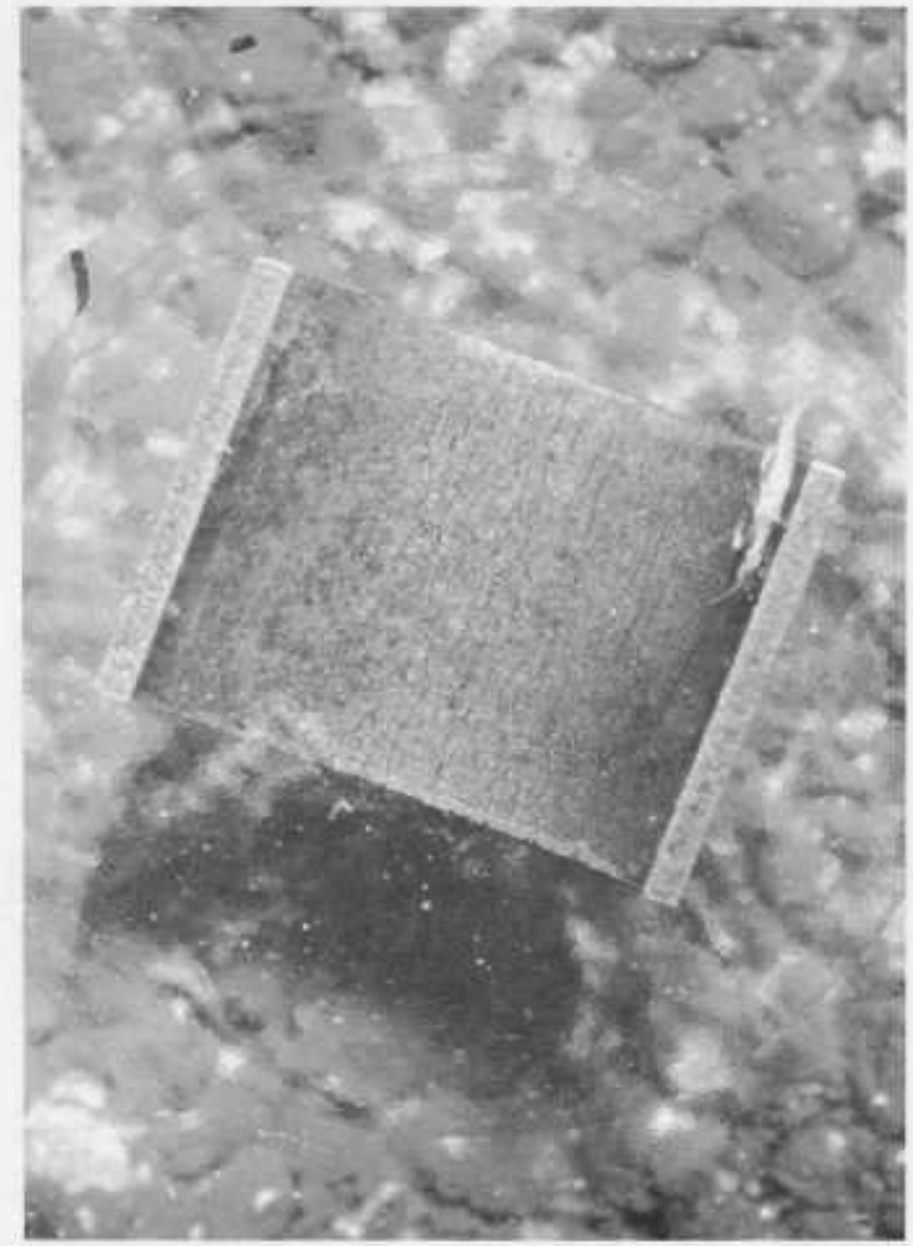

(b)

Fig. 10. Longitudinally Oriented Intergranular Cracks That Occur on Inside Surface of Annealed Type 304L (welded) Stainless Steel Tubes Tested at $650^{\circ} \mathrm{C}$ at High and Low Strain Rates, (a) Rupture failure at $\dot{e}_{\mathrm{m}} \approx 1.4 \times 10^{-2} \mathrm{hr}^{-1}$. Mag. $\sim 9 \mathrm{X}$. Neg. No. MSD-54319. (b) Pinhole failure at $\dot{e}_{\mathrm{m}} \approx 4.2 \times 10^{-4} \mathrm{hr}^{-1}$. Mag. $\sim 9 \mathrm{X}$, Neg. No, MSD-54311. 


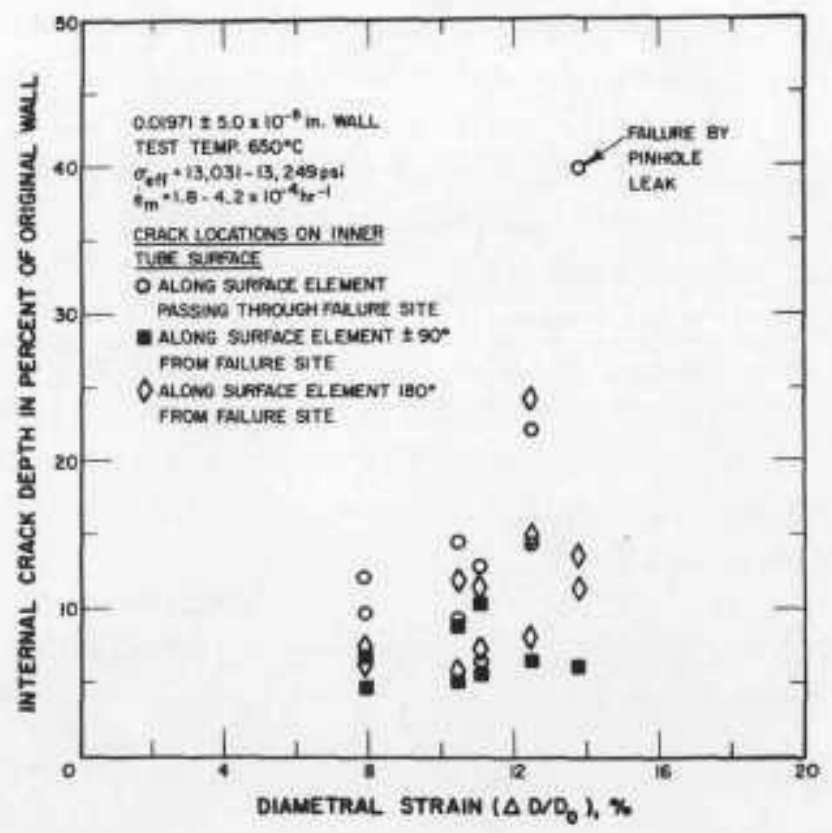

Fig.11. Internal Crack Depth vs Diametral Strain for a Type 304L (welded) Stainless Steel Tube Tested at $650^{\circ} \mathrm{C}$ and Low Strain Rate. Same specimen as shown in Figs, $6 \mathrm{~b}$ and 10b. Neg. No. MSD -54306 .

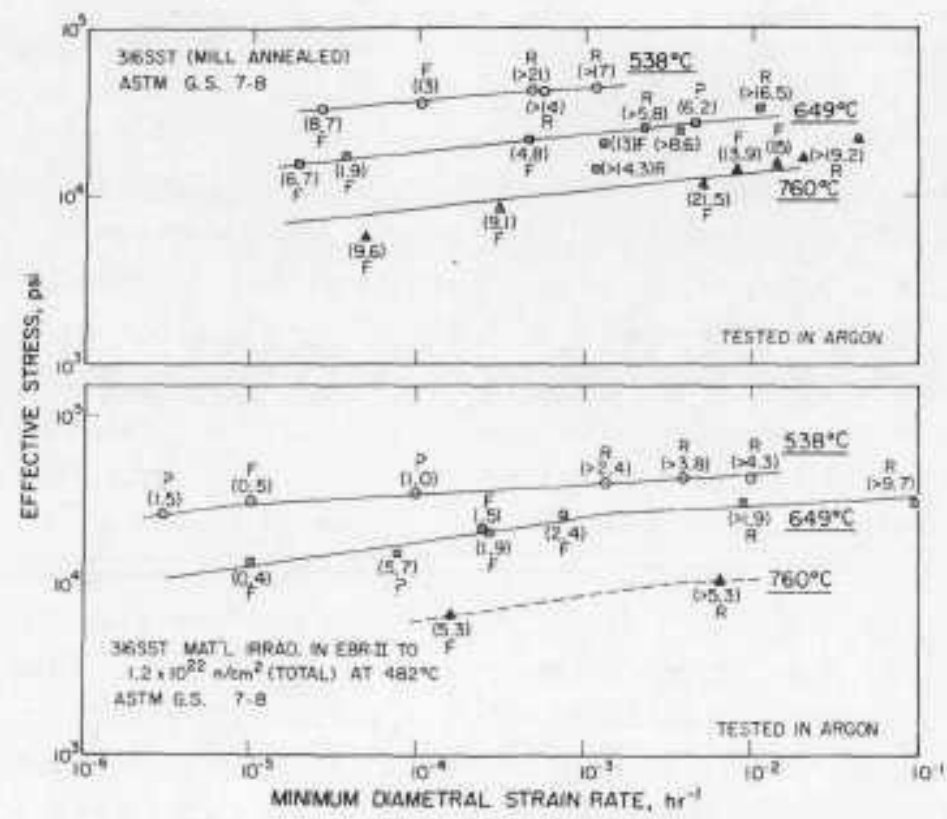

Fig. 12. Effective Stress vs Minimum Diametral Strain Rate fot Annealed and EBR-II Irradiated Type 316 Stainless Steel Tubes Tested at $538-760^{\circ} \mathrm{C} .{ }^{9}$ Neg. No. MSD -54366 . 
SRS increases, and the specimen should exhibit a tendency toward greater mechanical stability. However, GBS becomes significant in this region, and Hart ${ }^{8}$ proposes that uniaxially loaded specimens will fail by intergranular fracture. Applying similar reasoning to internally pressurized thin-wall tubes leads to the conclusion that the intergranular cracking will favor a pinhole perforation of the tube wall. This occurs by the interconnection of grain-boundary cavities and results in a failure at low $e_{f}$. The above argument concerning the change in SRS, failure mode, and $e_{f}$ is substantiated both by the present data in Fig. 1 and by the work of Lovell and Barker. 9 (Also, see data from Refs, 36-40 in the appendix.) Based on the experimental results, the following statements can be made concerning failures in pressurized thin-wall tubes:

1. Failure by pinhole leak is favored at high temperature and/or low strain rates.

2. Failure by violent rupture is favored at lower temperature and/or high strain rates.

3. Transition in the failure mode from the intergranular pinhole leak to the transgranular violent rupture will shift to higher strain rates with increasing temperature.

4. Failure strain decreases as the temperature increases or the strain rate decreases, because of the increase in GBS.

5. Time to failure will be determined as usual by the strain rate and the failure strain.

The experimental results in Figs, 2-5 substantiate the presence of GBS during plastic deformation. Figure 2 shows that the decrease in density $\left(-\Delta \rho / \rho_{0}\right)$ of the austenitic stainless steel due to cavity formation has a linear time dependence at $\dot{e}_{m}=4.2 \times 10^{-4} \mathrm{hr}^{-1}$, after an appreciable amount of accumulated strain. The trend of these data suggests that in the earlier stages of plastic deformation the density decrease exhibits a nonlinear time dependence and that a high initial rate of cavity formation prevails. This behavior is consistent with the observations of Gittins ${ }^{17}$ for polycrystalline copper creep tested at $400^{\circ} \mathrm{C}$. In the region of linear density change, Gittins concluded that the observed density decrease corresponds to cavity growth by vacancy diffusion. Grain-boundary sliding is important to the nucleation of cavities during the initial stages of plastic deformation. The cavities are not nucleated spontaneously, but rather as a function of time over a finite range of initial plastic deformation. In Fig. 2, the curve for $\dot{e}_{m}=1.4 \mathrm{x}$ $10^{-2} \mathrm{hr}^{-1}$ shows a density change with a higher power dependence on time, which suggests the existence of more than one mechanism for cavity for mation. The possibility of an additional mechanism for cavity formation at the higher strain rate is supported by the transverse sections of the density specimens shown in Figs. 3 and 4 . Figure 3 is a section at the pinhole failure that developed at the lower value of $\dot{e}_{m}\left(\approx 4.2 \times 10^{-4} \mathrm{hr}^{-1}\right)$. It shows 
a predominance of grain-boundary cavities, grains that are nearly equiaxed, and evidence of GBS. ${ }^{18,19}$ Figure 4 is a section at the site of the violent rupture that occurred at the higher $\dot{e}_{m}\left(-1.4 \times 10^{-2} \mathrm{hr}^{-1}\right)$. It shows grainboundary cavities that extend into the grain matrix and elongated grains. Scanning-electron micrographs of the fractured surfaces of the pinhole leak and the violent rupture failures presented in Figs. 3 and 4 are shown in Figs. 5a and b, respectively. The micrograph in Fig. 5a is typical of transgranular fracture that occurs at high strain rates. In contrast, the grain facets shown in Fig. $5 b$ are associated with intergranular fracture at low strain rates. The evidence in Figs. 3-5 supports the conclusions presented in the preceding paragraph that GBS becomes important at lower strain rates.

Typical specimen profiles for failures by violent rupture, pinhole leak, and fissure that occur in internally pressurized thin-wall tubes are shown in Figs. 6a, b, and c, respectively. A magnified view of each failure mode is shown in Figs. 7a, b, and c. Strain-profile measurements have been made at several time intervals for the specimens shown in Figs. 6 and 7. The strain-profile curves are given in Fig. 8 and illustrate the progressive development of mechanical instability. It is evident from Fig. 8 that the localized plastic strain is much lower for the pinhole and fissure failures than for violent rupture. The amount of localized plastic strain increases with the strain rate and with changes in failure mode. This behavior is consistent with the concept discussed earlier that the SRS is low in the region of high strain rates, which results in an enhancement of plastic instability. But this does not mean that the tube specimens are completely stable at the lower strain rates where the SRS is higher. Rather, the intergranular pinhole failures are usually observed at sufficiently low total deformations; therefore, plastic instability has not yet developed, or is in the early stages of development but has not progressed appreciably.

The observed effect of an artificially introduced defect supports the conclusion of plastic-instability enhancement at higher strain rates. If the sole consequence of an artificial defect is stress concentration at the defect site, one would expect enhanced crack (defect) propagation at both high and low strain rates. This is not observed experimentally. The experimental results show that the artificial defect exerts an effect only at higher strain rates. This is directly related to the concept of mechanical instability, as proposed by Hart. ${ }^{4}$ The pressurized specimen is less stable at the higher strain rates, and the degree of instability may be inferred by the relative rate of local deformation as compared with the average deformation. The introduction of a local defect with orientation $\beta=0^{\circ}$ enhances the rate of local deformation at the defect site without affecting the average deformation rate for the remainder of the specimen. Failure then occurs at a low value of average strain. At lower strain rates, the specimen is inherently more stable, and GBS will be the controlling failure mechanism. In the region of lower strain rate, the failure strain will decrease, and 
plastic instability will not develop, or it is in the early stages of development with no perceptible progress before pinhole failure occurs. Therefore, the artificial defects described earlier will have no observable effect. In the intermediate-strain-rate range (Fig. 8 b), failure can occur by pinhole leak with accompanying local strain at a specimen location free of mechanical defects. However, if a defect with orientation $\beta=0^{\circ}$ is introduced, the enhancement of mechanical instability may change the failure mode from pinhole leak to violent rupture (Fig. 9b). The strain-profile curve shown in Fig. $8 \mathrm{~b}$ for intermediate strain rates is evidence that GMD and GBS are omnipresent and competing failure mechanisms.

Experimental results also show that the location (bore versus surface) and orientation $\left(0^{\circ} \leq \beta \leq 90^{\circ}\right)$ of a defect can affect both the failure site and $e_{f}$ at high strain rates. An analysis by Yaggee and Wang ${ }^{20}$ shows that, for a given internal pressure, the stress intensity at a defect site will decrease as the defect location changes from the bore to the surface and its orientation changes from $\beta=0^{\circ}$ to $\beta=90^{\circ}$. This orientation dependence is consistent with the experimental observations of Lauritzen et al ${ }^{21}$ The specimen shown in Fig. $9 \mathrm{c}$ had two identical artificial defects with orientations of $\beta=0^{\circ}$. One defect was located on the surface 1.75 in. from a reference mark; the other was located on the bore 2.75 in. from the same reference mark. It is obvious that the specimen failed at the bore-defect site. The specimens in Figs. $9 \mathrm{a}$ and $\mathrm{b}$ each had a single artificial defect oriented at $\beta=0^{\circ}$ located on the surface and bore, respectively. All specimens in Fig. 9 failed at the defect site, which supports the contention that defects enhance mechanical instability at higher strain rates.

Figure 10 shows the presence of incipient cracks on the inner surface of tubes creep-tested at $650^{\circ} \mathrm{C}$ under biaxial load and high and low strain rates. The depth and distribution of these cracks are shown in Fig. 11 as a function of local diametral strain and position away from the failure site for a specimen that failed by pinhole leak at an intermediate strain rate. The existence of these incipient cracks and their failure to propagate is a qualitative measure of the relative mechanical stability of the specimen at intermediate strain rates.

It is worth noting that violent rupture may follow a pinhole failure if sufficient gas pressure is maintained to sustain a relatively high strain rate. This was observed in the present work. On several, although infrequent, occasions during tests at intermediate strain rates $\left(\dot{e}_{\mathrm{m}} \approx 10^{-4} \mathrm{hr}^{-1}\right.$ ) in the temperature range of $550-650^{\circ} \mathrm{C},{ }^{22}$ the pinhole leak was first detected by a one- to two-decade decrease in furnace vacuum with no change in specimen pressure. Within minutes this was followed by a sudden and gross loss in specimen pressure, which is the typical symptom of a speciment rupture. In each case, this phenomenon occured in specimens that exhibited signs of increased local deformation similar to that shown in the strain-profile curve in Fig. 8 b. 
The discussion so far has not involved a detailed concern for the effects of such metallurgical variables as second-phase particles, grain size, radiation damage, and cold work. From the mechanical-stability point of view, these variables can alter the SRS and the work-hardening behavior of a material and thereby influence its plastic instability. Some of these variables may enhance crack nucleation and propagation and therefore alter the creep-to-rupture property of the material. ${ }^{23}$ Grain-boundary behavior will also depend on these variables. For example, second-phase particles in the grain boundary may decrease the GBS rate and result in a beneficial effect at low strain rates. However, at high strain rates these same particles may serve as sites for crack nucleation and cause embrittlement. The matrix and grain-boundary mechanisms involved in most of these cases are not completely understood. However, the data from the present work, as well as that reported in the literature, indicate that the magnitude of these effects can be significant. The effect of grain size on the failure mode and failure strain is illustrated in Figs. 13 and 14. These figures show the failure profile and the strain-profile curve for a $\mathrm{V}-20 \mathrm{wt} \% \mathrm{Ti}$ alloy specimen tested at $650^{\circ} \mathrm{C}$ and a strain rate of $1.3 \times 10^{-3} \mathrm{hr}^{-1}$ for the smaller-grain-size specimen and $2.1 \times 10^{-4} \mathrm{hr}^{-1}$ for the larger-grain-size specimen. ${ }^{24}$ The larger-grain-size specimen failed by pinhole leak at low total strain $\left(e_{f} \approx 3 \%\right)$ without exhibiting any plastic instability. The strain

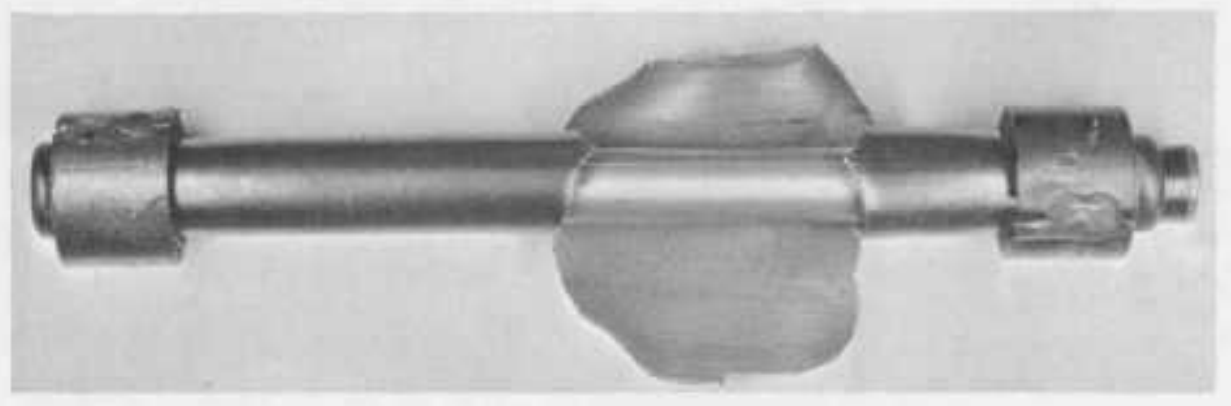

(a)

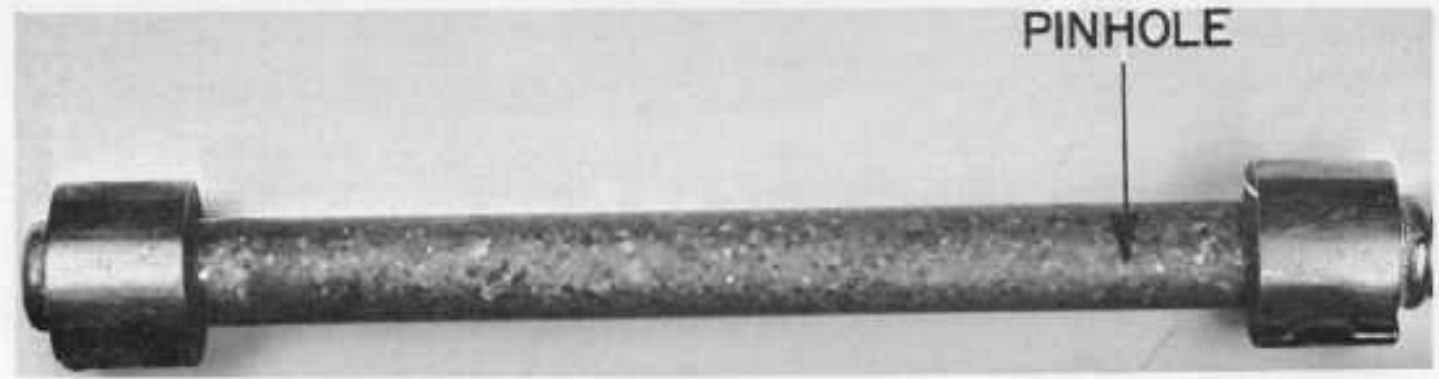

(b)

Fig. 13. Profiles of Rupture and Pinhole Faflures in V-20 wt \% Ti Alloy Tubes Tested at $650^{\circ} \mathrm{C}$ at High and Low Strain Rates. ${ }^{35}$ (a) Transgranular plastic-instability failure at $\dot{e}_{\mathrm{m}} \approx 1.3 \times$ $10^{-3} \mathrm{hr}^{-1}$. Failure strain $>10 \%$. ASTM grain síze 7. Mag. $\sim 1 \frac{1}{16}$ X. Neg. No. MSD-45647. (b) Intergranular failure due to grain-boundary sliding at $\dot{e}_{m} \approx 2.1 \times 10^{-4} \mathrm{hr}^{-1}$. Faflure strain $\sim 3,2 \%$. ASTM grain size <1. Mag. $\sim 1 \frac{1}{2}$ X. Neg. No. MSD -45645 . 


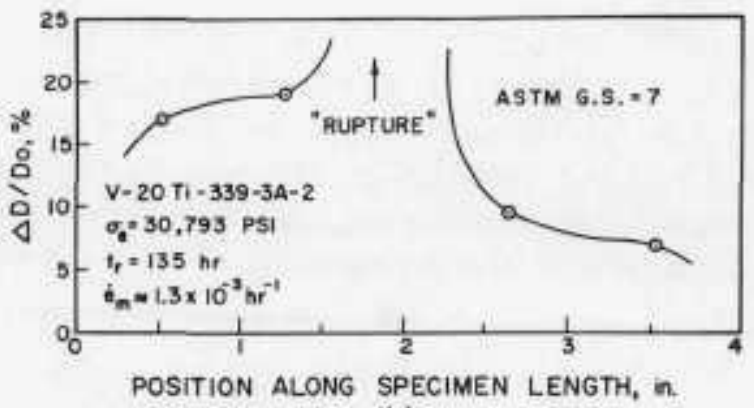

(a)

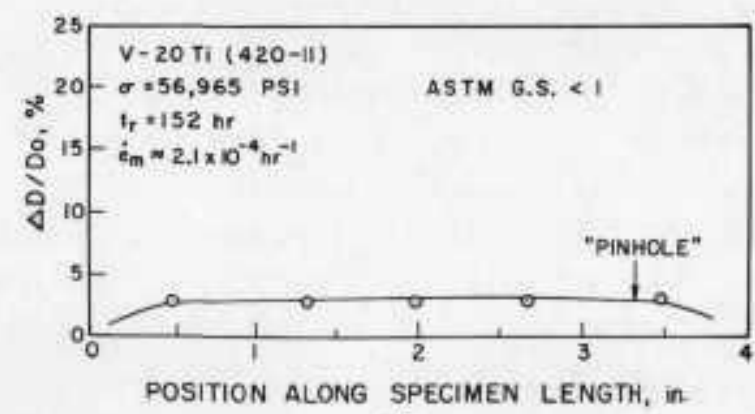

(b)

Fig. 14, Strain-profile Curves for $\mathrm{V}-20$ wt $\% \mathrm{Ti}$ Alloy Tube Fallures Shown in Fig. 13. (a) Transgranular plastic-instability failure. (b) Intergranular pinhole failure. Neg. No. MSD-54374. at failure for this specimen is lower than those shown in Figs. $8 b$ and c, which were obtained in stainless steel specimens of smaller grain size. An interesting fact about this specimen is that its grain size was greater than the wall thickness (grain size $\ll$ ASTM 1). The large grain size favors failure by pinhole leak. The data of other investigators (Fig. 12 and the illustrations in the appendix) include some interesting effects of cold work, radiation damage, and aging on the failure mode and failure strain of internally pressurized tube specimens. These variables shift the transition in failure mode (violent rupture to pinhole leak) to appreciably lower strain rates when compared with data for annealed specimens tested at the same temperature $\left(\mathrm{T} \approx 0.5 \mathrm{~T}_{\mathrm{m}}\right)$. This shift in transition of the failure mode to lower strain rates is accompanied by a decrease in $e_{f}$. Because cold work and radiation damage will induce severe microstructural changes in the material (including enhancement of precipitation and segregation), the embrittlement responsible for the lower ef values probably involves complicated processes.

The following section discusses the application of these deformation mechanisms and failure modes and the effect of metallurgical variables with regard to the formulation of failure criteria for fuel-element cladding.

\section{FAILURE CRITERIA}

Failure criteria are needed for both the design of a reactor fuel element and the safe operation of the reactor. The criteria should embody considerations of failure mode and failure conditions so that the consequences of fuel-element failure can be evaluated from the standpoint of reactor safety. Special attention must be given to abnormal operating conditions. ${ }^{25}$

This section considers cladding failure due to fuel and fission-gas loading. However, no attempt is made to discuss either the thermalhydraulic limitations of the fuel element or the conditions that lead to local cladding melting. 
Existing fuel-element failure criteria are generally based on arbitrary limits placed on cladding strain, strain ratios (uniform versus total strain), and fraction of remaining usable element life. ${ }^{26}$ The experimental results presented earlier indicate that these quantities, which are the basis for existing failure criteria, are affected in various ways by service conditions (temperature, stress, strain rate, and environment) and material parameters ( $y, m$, grain size, composition, and microstructure). The experimental results presented earlier also illustrate an orderly transition in the failure mode as the test conditions and material parameters are altered. In this section it will be shown how these experimental results can be related to failure criteria, and comments will be made on the effects of radiation damage, sodium environment, and fission-product attack.

Cladding loading by fission-gas pressure is considered first. In the absence of a reactor environment, cladding failure by pinhole leak should be favored at high temperatures and low fission-gas pressures. Under abnormal conditions that lead to high fission-gas pressures, the failure mode is expected to be violent rupture. The transition between these two failure modes will occur at higher strain rates as the cladding temperature increases. As always, the cladding lifetime is a consequence of both the strain rate and the strain at failure. Detailed fuel-element failure criteria should account for these possibilities.

The embrittlement due to radiation damage is well documented in the literature based on postirradiation tensile and stress-to-rupture test results obtained under uniaxial and biaxial stress conditions. The radiation damage of interest to LMFBR in the intermediate temperature range $\left(400-600^{\circ} \mathrm{C}\right)$ is associated with the swelling phenomenon. Voids and interstitial loops are the main feature of the irradiation-induced microstructure. Embrittlement due to helium bubble formation, which willbe discussed later, will occur in a higher temperature range.

The data in Fig. 12 indicate that the embrittlement due to void and loop formation lowers the strain at failure in regions where pinhole as well as rupture failures predominate. Figure 12 also shows that the transition in the failure mode from pinhole to rupture shifts to lower strain rates when compared with similar data for unirradiated, annealed specimens. From the point of view of mechanical stability, additional considerations must be taken into account in the application of postirradiation test data. The existence of irradiation-enhanced creep will increase the SRS ${ }^{27}$ and improve plastic stability. Therefore, the failure mode observed in postirradiation tests in the temperature region where irradiation-enhanced creep predominates may not be applicable to in-reactor conditions. Irradiation-enhanced creep could improve the compatibility between matrix deformation and grain-boundary deformation and result in a larger strain at failure than is found in postirradiation tests. This possibility has not been established 
experimentally to date. In the region of higher strain rates, irradiationenhanced creep will no longer be important, and the postirradiation test data may be applied directly to the formulation of fuel-element failure criteria.

The effect of fission-product attack on the cladding is a matter of some concern at present. This attack can occur as grain-boundary penetration and/or as a uniform bulk reaction over the length of the fuelcladding. The rate of this chemical attack is outside the scope of the present report. The following discussion will only concern the consequences of the chemical attack on the mechanical behavior of the cladding. It is probable that the attacked zone will lose its load-carrying capacity, thus decreasing the load-carrying capacity of the cladding in that region. Therefore, the effect of the chemical attack on mechanical instability may be analogous to that of artificial defects of different geometries. Inasmuch as the present work demonstrated that artificial defects exert an effect on cladding behavior only in the higher-strain-rate region, where irradiation-enhanced creep is less important, it might be possible to perform laboratory tests that simulate fission-product attack by selecting artificial defects of suitable sizes and geometries. Examples of this test approach are shown in Fig. 15.

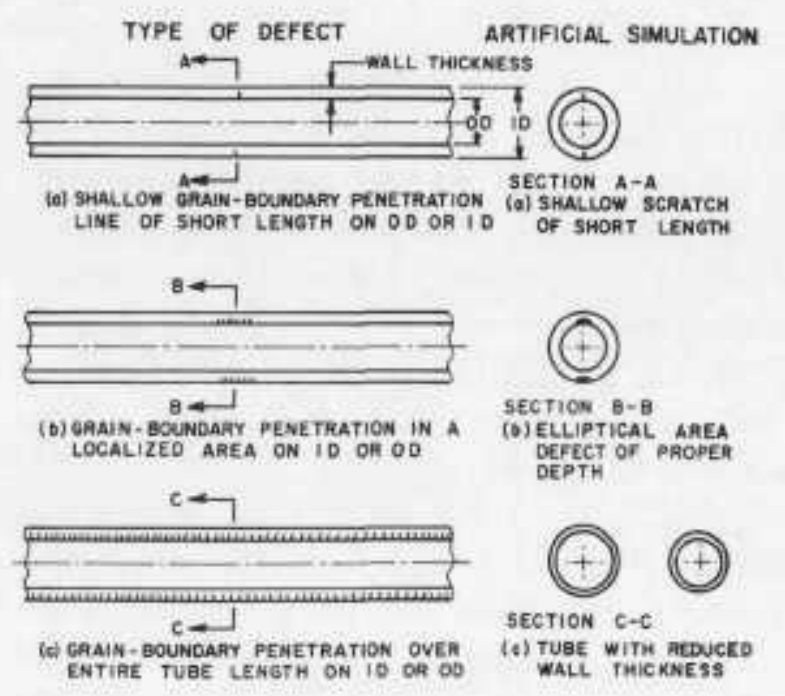

Fig. 15. Mechanical Simulation of Grain-boundary Penetration in Thin-wall Tubes by Fissionproduct Attack. Neg. No. MSD-54376.
A short scratch may be used to simulate mechanically a single penetrated grain boundary; an ellipsoidal defect may be used to simulate local grain-boundary penetration over several grains: and an overall reduction in wall thickness may be used to simulate uniform grain-boundary penetration or bulk attack over a significant portion of the specimen length. In the lower-strain-rate region, pinhole failure predominates, and the resultant failure strain is low. The effect of limited fissionproduct attack would then be expected to be less important.

Helium-bubble embrittlement ${ }^{28,29}$ and the exchange of nonmetallic elements (such as carbon and nitrogen) between the stainless steel and the sodium coolant ${ }^{30}$ are the two additional factors to be considered. Helium-bubble formation in the cladding becomes important in the upper portion of the fuel element, where the temperature is higher. Decarburization of the cladding is also favored in this region. It has been demonstrated that both phenomena cause microstructural changes that affect the rupture life, strain at failure, and nature of grain-boundary cracking. ${ }^{28,29,31}$ It should also be noted that thermalaging 
alone will alter the rnicrostructure of austenitic stainless steels. ${ }^{32}$ The present work has shown that the failure mode and the strain at failure that result from grain-boundary mechanisms and mechanical instability are unique to the thin-wall tube configuration under internal gas-pressure loading. It is therefore important that data on the failure mode and strain at failure be obtained from biaxial creep-to-rupture tests on pressurized thin-wall tubes that will be relevant to the formulation of fuel-element failure criteria. Although uniaxial tension tosts are easier to perform. at present no way is known to predict the creep and failure behavior of preasurized thin-wall tubes from uniaxial data with sufficient confidence.

Fuel-element designs exist for which the cladding deformation occurs as the result of fuel swelling under normal reactor operating conditions, and some transient conditions. At high strain rates, where mechanical instability is the controlling failure mechanism, cladding loading by fuel displacement due to swelling will provide sufficient constraint to suppress or delay mechanical instability. Under such conditions, it is possible to realize higher failure strains than can be obtained in uniaxial tension or in biaxial tube creep-to-rupture tests under gas-pressure loading. This possibility is supported by certain observations on postirradiation tensile test results of irradiated material ${ }^{33}$ and by the results of mandrelloaded creep-to-rupture tests ${ }^{34}$ on unirradiated tube specimens. In postirradiation tensile tests, local ductility has been observed in the form of high reduction-in-area values for an ixradiated material that usually exhibits a low failure strain due to mechanical instability. The mandrelloaded tests showed higher strain failure values than those normally obtained from similar tests using internal gas-pressure loading. It may be concluded that an adequate faiture strain will be obtained at high strain rates when the cladding is loaded by fuel swelling.

A possible exception to this point of view may occur in case of a cracked fuel. This condition may cause high local stress and strain concentrations in the cladding. Some tests that wse mechanical simulation of cladding loading by fuel $\mathrm{s}$ welling, as well as tests that produce local stress and strain concentrations, should be included in the postirradiation test program. The present work shows that at higher temperatures and/ or lower strain rates, grain-boundary sliding will be the controlling failure mechanism in the case of internal gas-pressure loading. where mechanical instability is not of concern. This failure mechanism should be operative in the anme temperature and strain-rate region, where the cladding is loaded by fuel swelling, provided consideration is given to the effect of local strain concentrations that arise from the possibility of cracked fuel.

Under internal gas-pressure loading, cladding deformation ceases, and failure occurs when the cladding wall is perforated by a pinhole leak, if the internal pressure is exhausted at a sufficient rate. In contrast, 
cladding deformation can continue after failure by pinhole leak when the cladding is loaded by fuel swelling, which leads to progressive crack growth. In the latter instance, a complicated sodium-fuel interaction could occur, and its consequences on crack propagation in the cladding is unknown at present. Because this phenomenon is associated with the subject of fuelelement life after cladding failure, it will not be discussed in the present report.

In summary, the present data and the acompanying discussions show the dependence of the failure mode and strain at failure of fuelelement cladding on stress, temperature, strain rate, and method of loading (internal gas pressure versus fuel swelling). Fuel-element modeling studies, as, for example, the LLFE Code, ${ }^{35}$ can be used to predict operating stresses, temperatures, strain rates, and loading methods for a given fuelelement burnup. However, note that cyclic effects will occur during normal power-reactor operation. The specific cyclic effects will depend upon the method of cladding loading, fuel cracking and healing, frictional forces be tween fuel and cladding, and temperature distribution. If the cyclic power profite under normal reactor operating conditions results in appreciable periods of cladding deformation at low strain rates, the chances for cladding failure by intergranular pinhole leak will be enhanced. Thus far, no systematic information, either experimental or theoretical, is available to define specific cyclic effects and-predict their possible consequences on fuel-element failure. It is expected that the results based on static loading presented here can serve as a reasonable basis for the development of a failure criterion provided a safety factor 1 s included to account for the cyclic effects. Future work on cyclic effects should rely on fuel-element modeling studies as well as experimental observations to define the possible loading schemes that are relevant to actual reacto $r$ operations and thereby provide a means for a systematic study of cyclic effects on fuelelement failure. 


\section{APPENDIX}

Biaxial Stress-to-Rupture Data of Other Investigators

Additional biaxial creep-to-failure data of other investigators ${ }^{36-40}$ for austenitic stainless steel tubes are available, some of which are presented in Tables II and III and in Figs. 16-22. All tests were conducted under gas-pressure loading conditions.

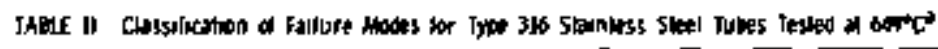

\begin{tabular}{|c|c|c|c|c|c|c|c|c|c|c|c|c|c|c|c|c|c|c|c|c|c|c|c|c|c|c|}
\hline \multirow[b]{2}{*}{ MeH } & \multirow[b]{2}{*}{ Constitan } & \multirow{2}{*}{$\begin{array}{c}\text { A5IT } \\
\text { Grats Silpe }\end{array}$} & \multicolumn{24}{|c|}{ Stress $\times 1000 \times 4$} \\
\hline & & & 20 & 21 & $n$ & 27 & 24 & 25 & 26 & 27 & 8 & 2 & 30 & 3 & $n$ & 33 & 4 & 35 & 36 & y & 38 & 9 & 4 & 41 & 4 & 4 \\
\hline \multirow[t]{3}{*}{ cto } & PO-CH & काष 5 & & & & & & & & 2 & & ! & & & & & & & & & & & & & & \\
\hline & PD-ANM & s & & & & & & & & & & & & & & & & & & & & & & & & \\
\hline & $P O \cdot C H$ & $5 \$ 6$ & & & & & & & & & & & & & & & & & & & & & & & & \\
\hline \multirow[t]{2}{*}{ IV } & $\mathrm{PD}-\mathrm{CW}$ & 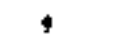 & & & & & & & & $\mathbf{I}$ & & 1 & $\mathbf{I}$ & & & & & & & & & & & & & \\
\hline & $\mathrm{PO} \cdot \mathrm{CH}$ & 5516 & & & & & & & & & & & & & & & & & & & & & & & & \\
\hline \multirow[t]{7}{*}{ WWCE } & PD-CWN & 4 & & & & & 1 & & 3 & & & $z$ & & & & $?$ & 1 & & & 3 & & & 3 & & & \\
\hline & $P Q \cdot A N N$ & เ & & 2 & & 2 & & $z$ & 2 & & & & 3 & & 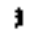 & & & & & & & & & & & \\
\hline & $\mathrm{PD}-\mathrm{CW}$ & 3516 & & & & & & & & & & & 3 & & 1 & $i$ & & & & 1 & & & & 2 & & \\
\hline & $P D-G N$ GH & , & & & & & & & & & & & & & & & & & & & & & & & & \\
\hline & PS.CW & 6 & & & & 1 & & & & & $\mathbf{I}$ & & & & & & & & & $\mathbf{J}$ & & & & & & 2 \\
\hline & P5-AHEN & 6 & & & & & & & & & & & & & & & & & & & & & & & & \\
\hline & PȘ-chN Ght & 6 & 1 & & & & & & & & & & & & & & & & & & & & & & & \\
\hline
\end{tabular}

soat irom fal 36

bonlure lyote

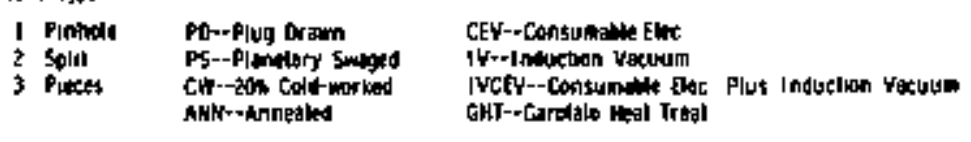

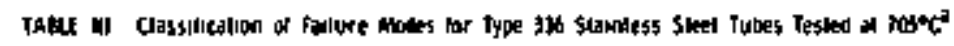

\begin{tabular}{|c|c|c|c|c|c|c|c|c|c|c|c|c|c|c|c|c|c|c|c|c|c|c|c|c|}
\hline \multirow[b]{2}{*}{$M+14$} & \multirow[b]{2}{*}{ Conguning } & \multirow{2}{*}{ Croin stito } & \multicolumn{22}{|c|}{ Stross $x$ lon pal } \\
\hline & & & II & 12 & 13 & Id & 15 & 16 & it & \# & $\overline{19}$ & 20 & 31 & $z$ & 23 & 24 & 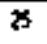 & 20 & 23 & 宛 & 29 & 3 & 31 & 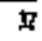 \\
\hline \multirow[t]{3}{*}{$\alpha Y$} & $P D=C M$ & 945 & & & & ] & & $\mathbf{I}$ & & $\mathbf{I}$ & & $\boldsymbol{t}$ & & $\downarrow$ & & $\mathbf{I}$ & & $\mathbf{I}$ & & $\boldsymbol{Z}$ & & $\mathbf{I}$ & & \\
\hline & PD-ANit & B & & & & ] & & $\mathbf{J}$ & & 2 & & 2 & & J & & 2 & & & & & & & & \\
\hline & $P D-C M$ & $\$ 516$ & & & & & & & & & & & & 1 & & 1 & & $\mathbf{I}$ & & 1 & & 2 & & \\
\hline \multirow[t]{2}{*}{$w$} & $P B-C W$ & 9 & & & & & & & & $\mathbf{1}$ & 1 & $\mathbf{I}$ & & 2 & & 2 & & 2 & & 2 & & $\mathbf{l}$ & & \\
\hline & $P O \cdot$ 네 & 558 & & & & & & & & & & $\mathbf{I}$ & & $\mathbf{I}$ & & 1 & & $?$ & & 1 & & 1 & & \\
\hline \multirow[t]{7}{*}{ InceV } & PQ-CW & 4 & & 1 & & & 1 & $z^{b}$ & $\mathbf{I}$ & 1 & & 1 & & 2 & $l^{*}$ & 3 & & J & $\mathbf{I}$ & 1 & & 2 & & \\
\hline & PD.AHN & 8 & & J & $\mathbf{I}$ & 3 & 7 & 1 & & 2 & & 3.7 & $z$ & 2 & & 2 & 3 & & & & & & & \\
\hline & $P(0-C W$ & 5 幽6 & & & & & $\mathbf{I}$ & & 1 & & $\mathrm{l}$ & 1 & 2 & 1,2 & & 1,2 & & 了 & 2 & $z$ & 2 & 3 & & \\
\hline & MalcW GHT & 4 & & & & & & & & & & $\mathbf{l}$ & & 1 & & 3 & & 3 & & 3 & & 3 & & \\
\hline & PS-CW & 6 & $\mathbf{I}$ & & 1 & & & I & & & & $\mathbf{I}$ & & 1 & & I & & i & & I & & 1 & 2 & \\
\hline & PS-dikin & 6 & & & & 1 & $\mathbf{I}$ & $?$ & & 2 & 2 & & $z$ & & 3 & & & 2 & & & 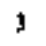 & & & \\
\hline & PS-CW CHI & 6 & & & & & & & & $\mathbf{I}$ & & & $\mathbf{I}$ & & & & & $\mathbf{I}$ & & & 2 & & & \\
\hline
\end{tabular}

\footnotetext{
Dab Irom Ref 30

Micropasined

Falust Iyte

1 Pintuole

PD-rPluq Oram PS..-Pantatary \$inaged

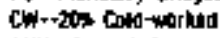

stustosinneded

CF.-Confundate Elx

IV-al Induchlon Vocuune

IVCtu.-Consumble Elec Plus Indudian varum

GHT- Groble hol Irent
} 


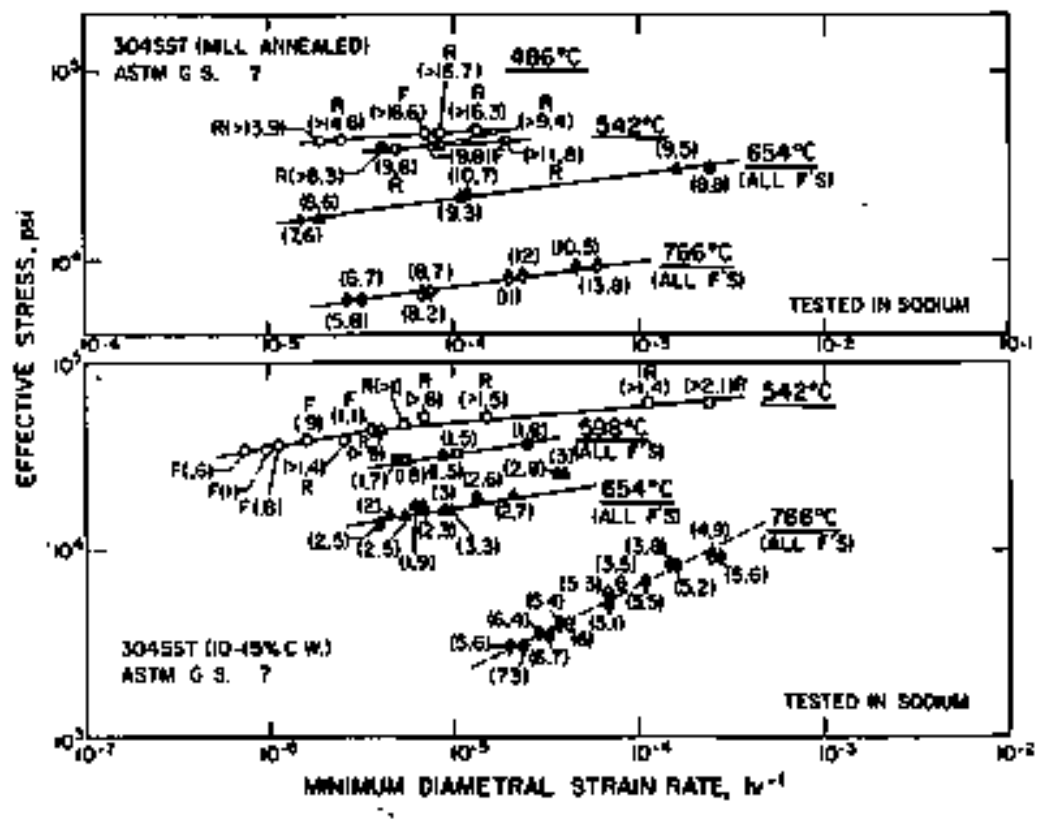

Fig. 16. Effective Stress v5 Minimum Diameral Stroin Rate for Annealed and Cold-worked Type 304 Stainless Sreel Tubes Tested at $486-766^{\circ} \mathrm{C}$. ${ }^{8}$ Neg. No. MSD-54364.

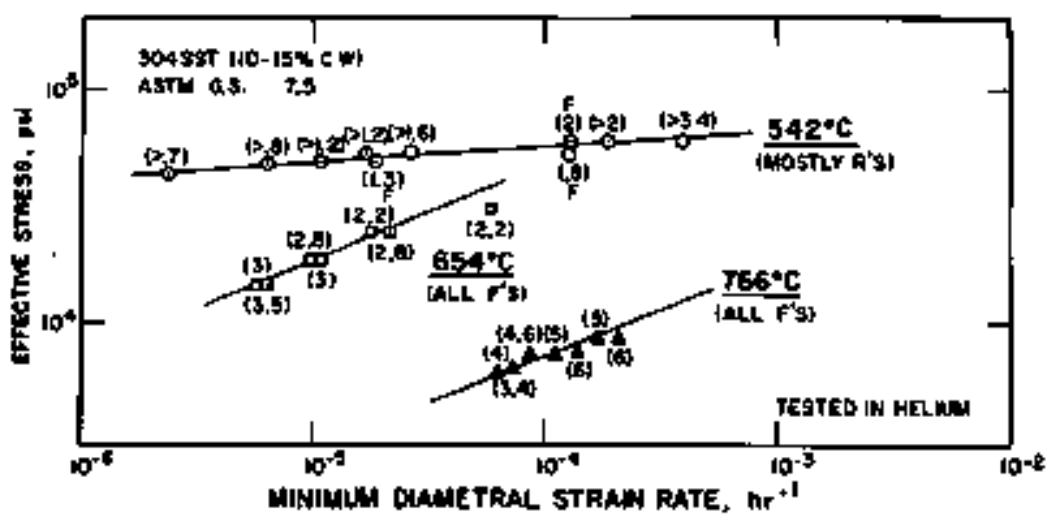

Fig, 17. Effective Stress vs Minimum Dismetral Stroin Rate for Cold-worked Type 304 stainless Steel Tubes Tested at 542-766*C.38 Neg. No. MSD-54372. 


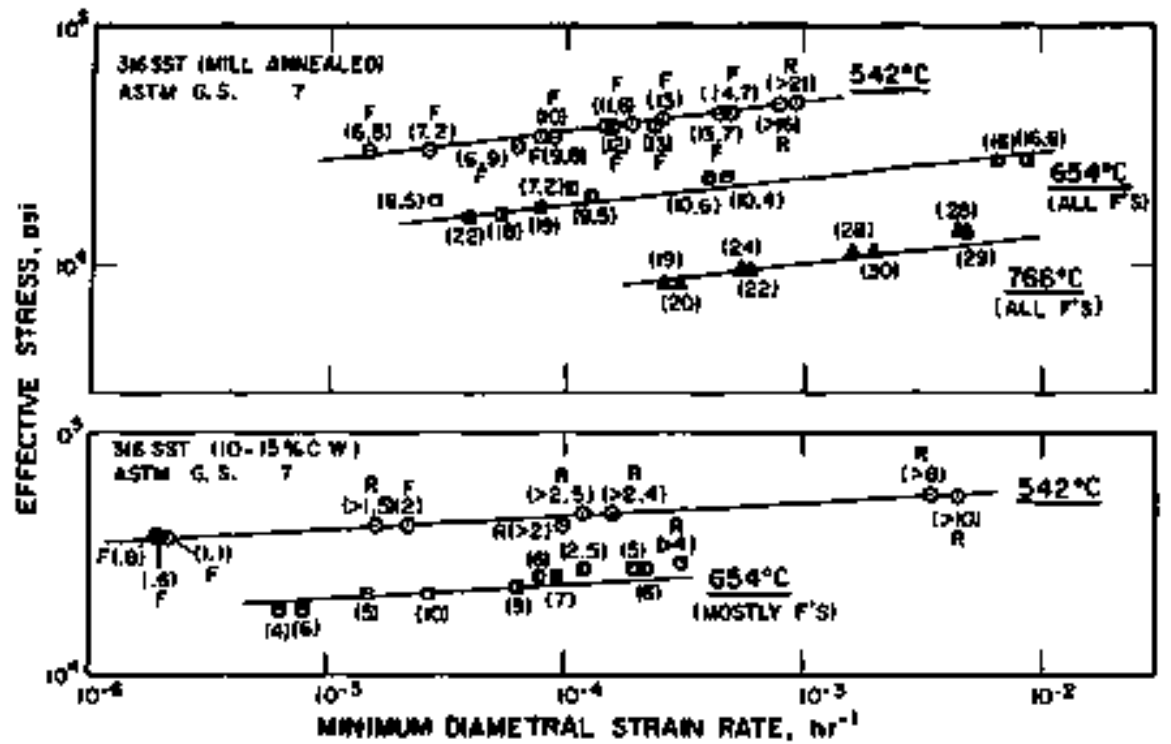

Fig. 18, Effective Stress vs Minimum Dlametral Stratn Rate for Annealed and Cold-worked Type 316 Stainless Steel Tubes Tested at $542-766^{\circ} \mathrm{C}$ in Sodium. 3B Neg. No. MSD-54369.

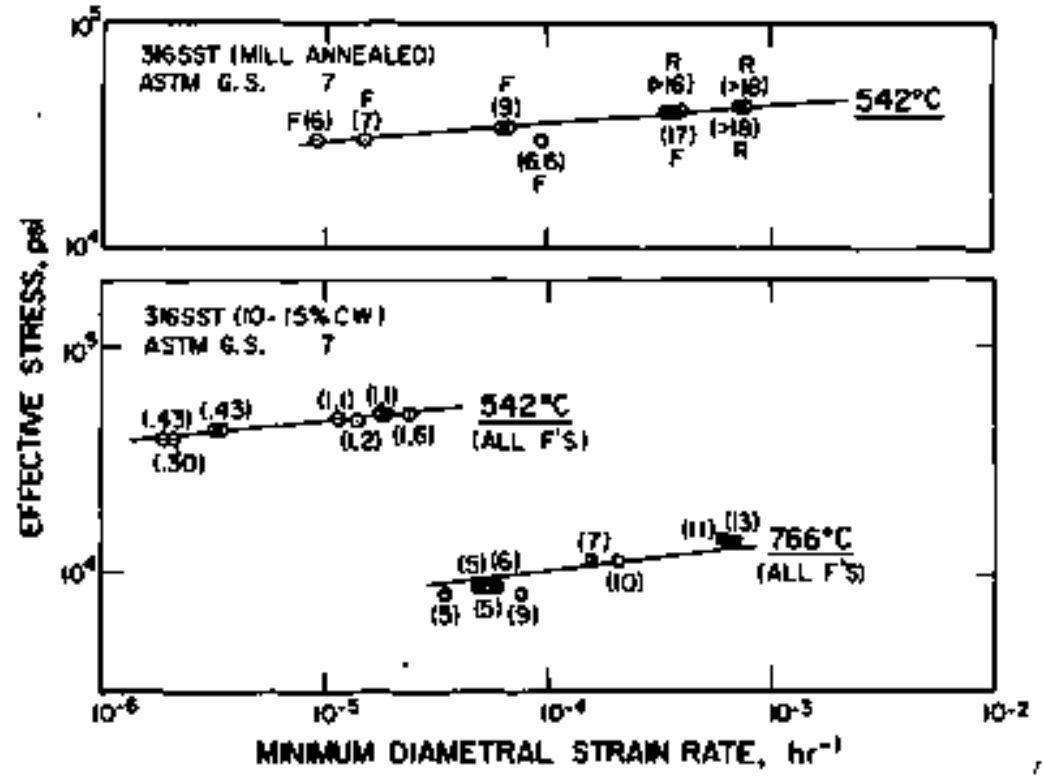

Fig. 19. Effective Stress vs Minimum Diamettal Strain Rate for Annesled and Cold-worked Type 316 Staialess Steel Tubes Tested at $542-766^{\circ} \mathrm{C}$ in Helium, 38 Neg. No. MED-54365, 


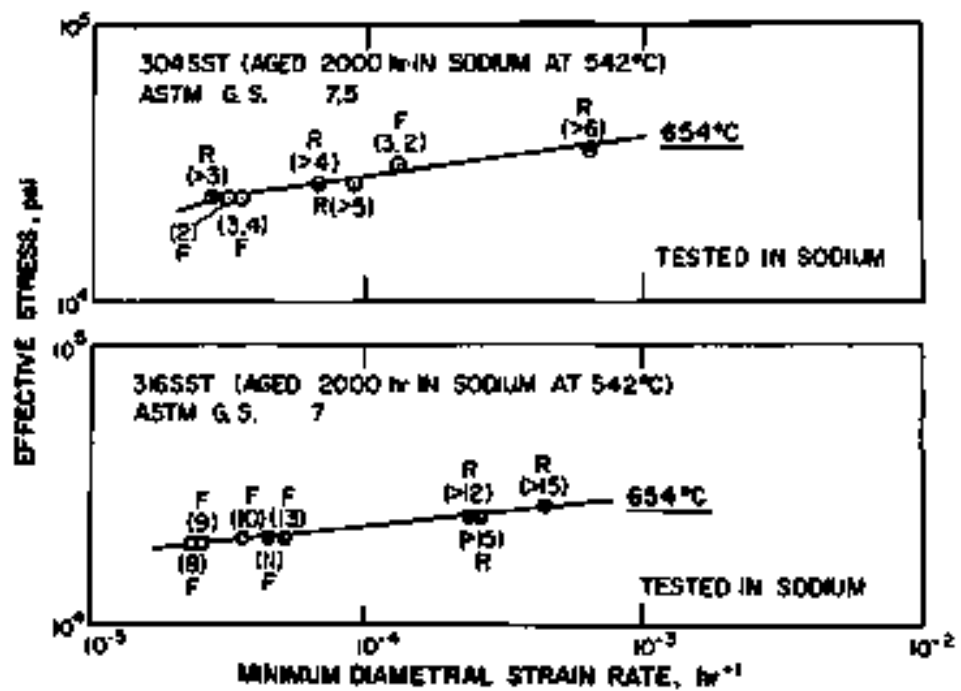

Fig. 20. Effective Suress vs Minimum Diamerral Strain Rore for Aged Types 304 and 316 stainless Steel Tubes Tested at $654^{\circ} \mathrm{C}$. . $^{8} \mathrm{Neg}$. No. MSD-54368.

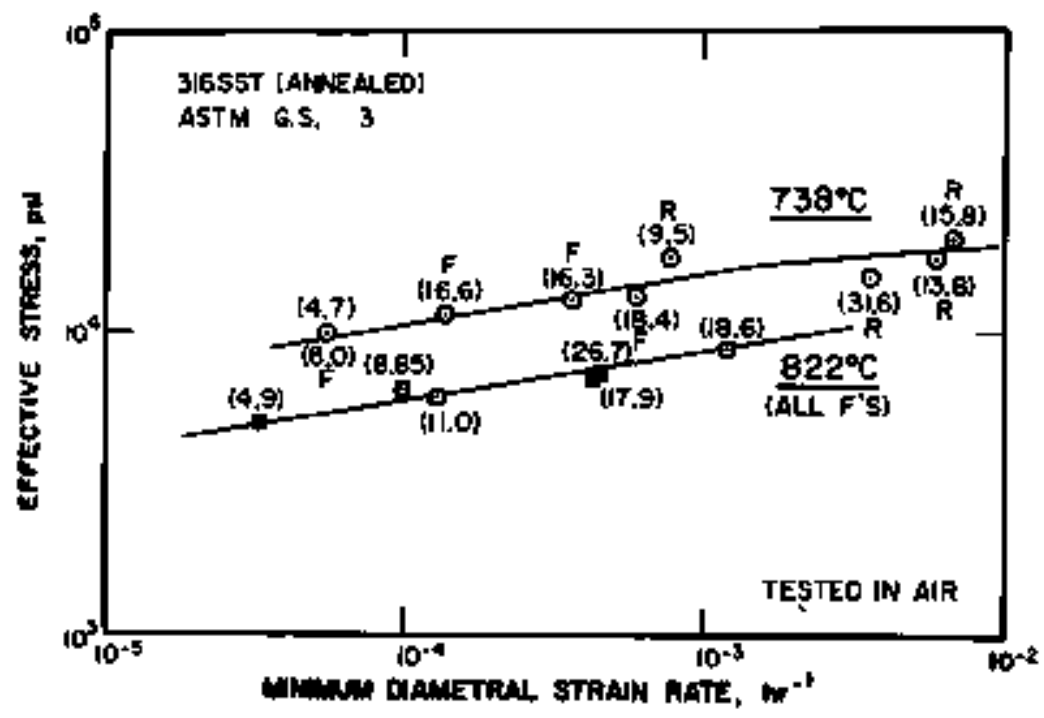

Fig. 21. Effective Suress vs Minimum Diametral Strain Rate for Annealed Type 316 Stainless Steel Tubes Tested at $738-822^{\circ} \mathrm{C} .40 \mathrm{Neg}$. No. MSD-54373. 


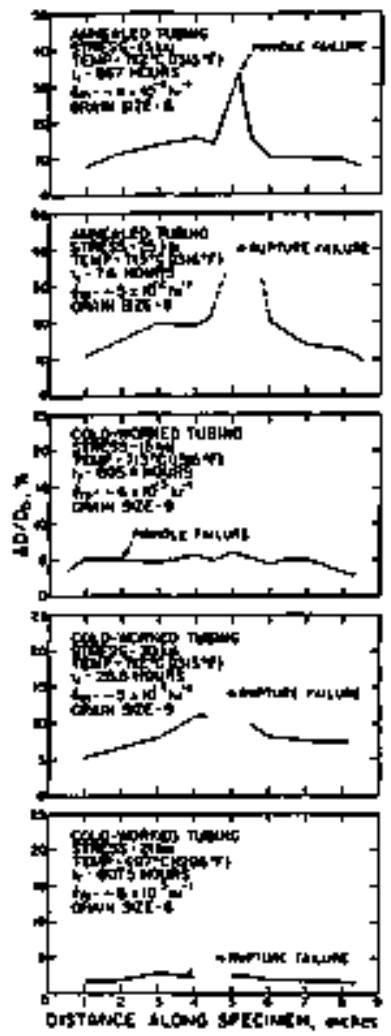

Fig. 22

Strain-profile Curves for Type 316 Stainless Sree! Tubes Tested at $697-713^{\circ} \mathrm{C}$. (Data from Ref. 36 .) Neg. No. MSD-56974.
The classification of failure modes in Tables II and $\amalg I$ shows a tendency toward pinhole and fissure failures at low stresses and, therefore, low resultant strain rates. The strain-profile curves given in Fig. 22 for annealed and cold-worked Type 316 stainless steel tubes are similar to those shown in Figs. 8 and 9, and indicate that pinhold-leak failures generally occur at lower strain rates and lower total strains than the rupture failures. Figure 22 also shows that, for a given grain size (ASTM $8-9$ ) and temperature $\left(-713^{\circ} \mathrm{C}\right.$ ), rupture failures in cold-worked tubes occur at lower strain rates ( $m \approx 5 \times 10^{-4} \mathrm{hr}^{-1}$ ) than in annealed tubes (ém $\approx 5 \times 10^{-2} \mathrm{hr}^{-1}$ ) under gas-pressure loading. Likewise, for a given microstructure (cold-worked material), grain size (ASTM 9 versus ASTM 6) can affect the strain rate ( $\dot{e}_{\mathrm{m}} \approx 6 \times 10^{-5} \mathrm{hr}-1$ versus $5 \mathrm{x}$ $10^{-4} \mathrm{hr}^{-1}$ ) and the strain at which failure by rupture might occur.

The stress-to-rupture data in Figs. $16-21$ are presented as curves of $\log \bar{\sigma}$ versus $\log \dot{e}_{m}$ for Types 304 and 316 stainless steel tubes in the annealed, cold-worked, and aged conditions. Pinhole and fis sure failures are designated by the symbol (F), and rupture failures are designated by the symbol $(R)$, as for similar data presented earlier in this report. The percent diametral strain at failure for each data point in Figs. $16-21$ is indicated by the number in parentheses. It is obvious from an inspection of Figs. 16-21 that pinhole and fissure failures (F) predominate at the lower strain rates, and rupture failures (R) predominate at the higher strain rates. In general, these data support the suggestion presented in Fig. l that intergranular pinhole failures will occur at higher temperatures and/or lower strain rates, at which GBS becomes significant, and the failure strain will be low. Transgranular rupture failures will occur at lower temperatures and/or higher strain rates, at which matrix deformation predominates. In the latter case, plastic instability will control the failure mode, and the failure strain will be higher. 


\section{ACKNOW LEDGMENTS}

We gratefully acknowledge, the assistance of J. W. Styles for performing the biaxial creep testa and the optical microscopy, and the assistance of $W$. F. Burke for preparing SEM fractographs of the fractured surfaces. Special appreciation is expressed to T. C. Reuther, K. M, Zwilsky, J. H. Shively, Constantine Spelaris, Eliot Duncombe, F. A. Nichols, R. W. Weeks, and C. Y. Cheng for their review and comments on the manuscript. 


\section{REFERENCES}

1. R. N. Stevens, Grain-Boundary Sliding in Metals, Met. Rev. 11, 129-142 (1966).

2. E. W. Hart, A Theory for Flow of Polyerystale, Acta Met. 15, 1545-1549 (1967).

3. E. W. Hart, A Phenomenological Theory for Plastic Deformation of Polycystalitine Netals, Acta Met, 15, 599-610 (1970).

4. E. W. Hart, Theory of the Tensile Test, Acta Met, 15, 351-355 (1967).

5. A Consideré, Ann. ponte, et chausseés 9, Ser. 6, 574-775 (1885).

6. W. T. Lankford and E. Saibel, Some Probleme in Unatable plastic Flow Under Biaxial Tension, Trans. AIME 171, 562-573 (1947).

7. I. S. ServI and N. J. Grant, Creep and Stress-Rtpture Behavior of Alwninum As a Function of Purity, Trans. AIME 191, 909-922 (1951).

8. B. W. Hart, Intergranulor Faiture, General Electric 69-C-334 (Sept 1969).

9. A. J. Lovell and R. W. Barker, Uniarial and Biatial Creep-Ritpture of 316 Stainless Steel after Fast Reactor Irradiation, WHAN-FR-19 (Sept 1970).

10. L. C. Walters, C. M. Walter, M. A. Pugacz, J. A. Tesk, R, Carlander, and Che-Yu Li, EBR-II In-Pile Creep Experiments on Staintess Steet Tubing, Travs, Am. Nucl, Soc. 13(1), 145 (1970).

11. F. L. Yaggee, J. W. Styles, and S. B. Brak, Semicutomatic Apparatus for Creep and Strese-mpture Tests of Thin-wall Fuel-otadding Tubes under Internat Gas-presaure Loading, ANL-7801 (Sept 1971).

12. R, J. Roarke, Formitae for Strese and Strain, McGraw-Hill, New York, 4th Ed., p. 298 (1965).

13. L. J. Cuddy, Internat Stresees and Structures Doveloped During Creep, Met. Trans, 1, 395 (1970).

14. P. W. Davieg and R. Dutton, on the Mechaniems of Tertiary Creep in Face Centered Cubio Metals, Acta Met. 1S, 1365-1372 (1967).

15. R. T. King, Biaxial Creep-Ripture of 0.2\% Ti - Modified Type $304 L$ Staintees Steel Tubing, 1969 Annual Meeting, Am. Nuc1. Soc., Seatcle, Hashington, June 15-19, 1969. Also Trans. Am. Nucl. Soc. 12(1), 135 (1969).

I6. M. M. Faxton, WADCo Corporation, Rlchland, Wash., private communteation, 1971.

17. A. Gittins, The Mechanical Cavitation in Copper During Creep, Metals Sci. J. 1, 214-216 (1967).

18. H. Brunner and N. J. Grant, Deformation Resulting from Grain Boundary Sidiing, Trans. AIME 215, 48-56 (1959).

19. J. L. Walter and H. E. Fine, Grain Boundary Sliding, Nigration, and Deformation in High Purity Alwminum, Trans. AME 242, 1823-1830 (1968). 
20. F. Ln Yageee and I-ChLh Wang, Effect of Defects on the Rupture Duetitity of Type 804 Stainiese Steel Tubes under Biaxiat Load, Am. Nuci. Soc. Wlater Meeting, San Eranclsco, Callf, (Nov-Dec 1969). Also-Trans. Am. Hacl, Soc, 12(2), 570 (1969).

21. T. Lautitzen, A. Kontes, and A. Conti, The Influence of Surface Defeats on the Short-Tem Mechanical Propertiea of Austenitic Stainiess'Steel Tubing, GEAP-13550 (Dec 1969).

22. F. L. Yaggee; unpublished work on the Biaxial Creep of Austentt1c Stainless Steels.

23. F. Garofalo, Fundonentals of' Cresp and Croep Rupture in Hetals, MacMIllan; Ned-York (1965).

24. F. L, Yaggee and E, R. Gilbert, "Effect- of Sodiam Exposure on the Mechantcal Propertiea of Potential Fuel Jacket Alloys at 550-700 $\mathrm{C}, "$ In Proc. IAEA Stmp. on Alkati Metal Coolants-Cormosion studies and System Operating Experience; Vienna, Nov 28-Dec 2, 1966, International Atonic Energy Agency, Vienna, Pp, 215-229 (1967).

25. M. D.: Cacelli et at, Fuel fod Design Limit ana Traneient survival Criteria, WARD-4135-6 (July 1970).

26. T. R. Bump, SWELL: A FORTRAN-II Code for- Estimating Lifetimes of Mixed-oxide Fuet. Blemente; ANL-7681 (to be published).

27. S. D. Harkneas, J. A. Tesk, and Che-Yu Li, An Analysis of Fast Neutron Effects on Votd Bortation and Creep in Netats, J. Nuc1. Appl. and Tech. 9,24 (1970).

28. D. Kramer, Ko R. Garr, C. G. Rhodes, and A. G. Pard, "The Effects of Heliam on the High Temperature Ductility of Sanvik 12R72Hv and Inco In-744X," in Irradiation Effeats on Structurat Alloys for Nuclear Reactor Applioations; ASTM-STP-484, p. 509 (1970).

29. K. R. Garr, D. Kraner, and C. G. Rhodes, The Effect of Helium on the Strese-Ruptume Behavior of Type 316 Stainless Steel, Met. Trans. 2, 269-275 (1971).

30. K. Nateean and T. F. Kassner, Thermodynomic and Kinetis ABpects of Carben Tranoport in Sodirm-Steet Systems, J. Nuc1. Mater. 37(2), 223 (1970).

31. K: Nacesan, T, F. Kassner, and Che-YucL1, Effect of Soditum on Mechaniaat. Properties and Priation-wear Behavior of LMFBR Materiats: $A$ Review; submitted for publication in Reactor Tech. (1972).

32. R. St1ckler and B. Weiss, Phase Instabilities During High Temperature Exposure of 316 Austentic Stainless Steel. Scientific Paper 70-104STABL-P1, Westinghouse Research Labs., Pittsburgh, Pa. (July 9, 1970).

33. D: Frank1in, The Dutility of Imadiated Type. 304 Stainiess steel and Its Application to Buel Eloment Design; submtted for publication in $\mathrm{J}$. Nucl. Mater.

34: Genaral Elootric (Sunnuale) Muenty-Ninth Quanterly Report, GEAP-5753, p. 83. (Nov 1968-Jan 1969).

35. V. Z. Jankus and R: W. Weeks; LIFELI, a FORTRAN-IV Computer Code for the Pridietion of Fast-reactor Fuel-element Bshavior, ANL-7736 (Nov 1970). 
36. Stainless Steel Cladding Development Quarterly Progress Report for the Feriod Inding December 31, 1970, WARD-4135-14 (1971).

37. W. T, Lee, Biasial Stress-Rupture Properties of Austenitio Staintess Stee ls in Static Sodium, AI-AEC-12694 (June 1968).

38. D. F. Atk1ns, Stress-Rupture Behavion of Types 304 and 316 Staintess Steel cladding in High-Temperature Static Sodiun, AI-ABC-12976 (Sept 1970).

39. J. B. Conway and P. N. Flagella, Physical and Nechanical Properties of Reastor Materials, GEMP-727 (Dec 1969).

40. G. H. Rowe, J. R. Stewart, and $\mathrm{k}, \mathrm{N}$. Burgess, Capped End, Thin-Wall Thbe Creep-fuptare Behavior for Type 316 Staintess Steet, J. Basic Eng. 85, 71-86 (1963). 